
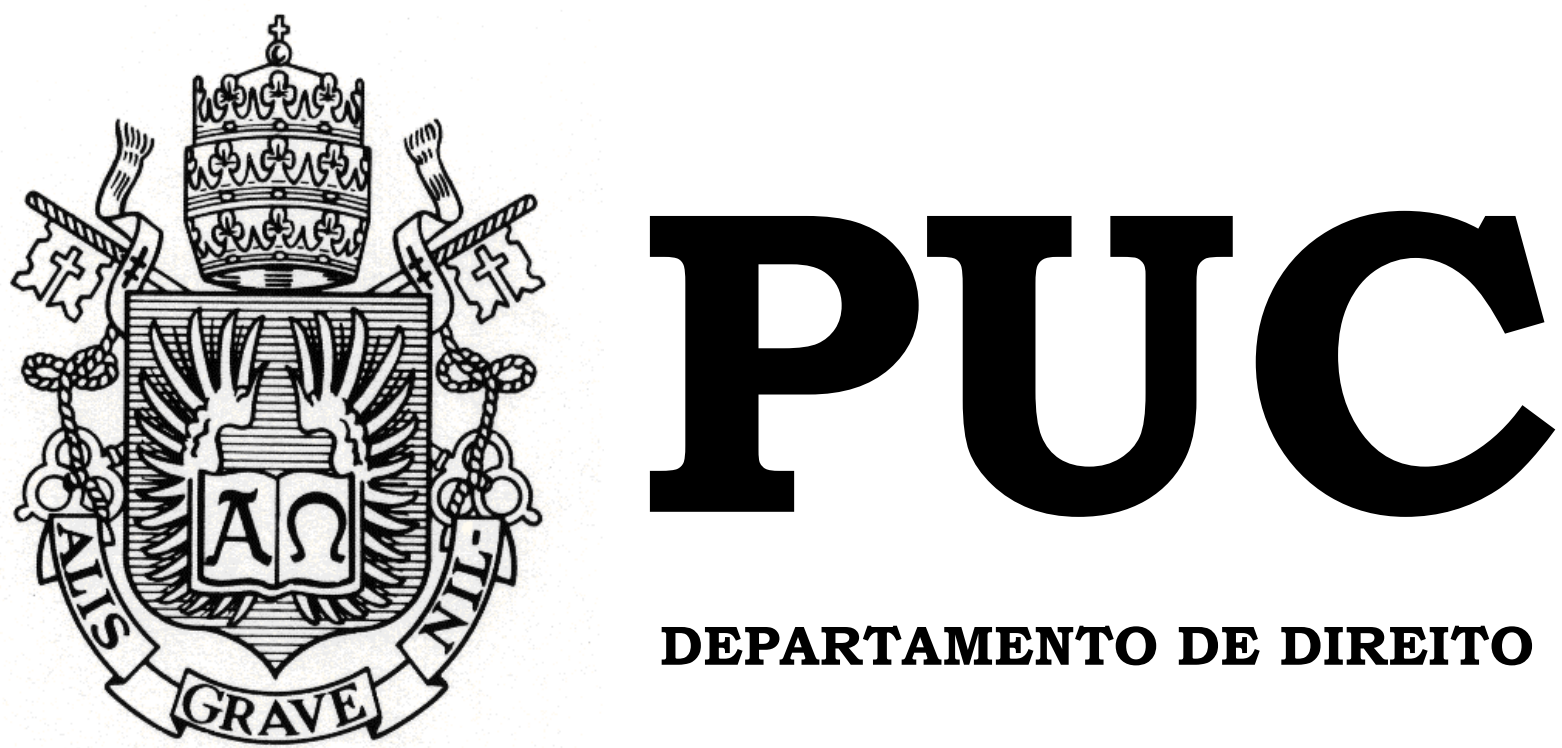

DEPARTAMENTO DE DIREITO

\title{
A IMPUGNAÇÃO DO ÁRBITRO SEGUNDO O ESTẤGIO DA ARBITRAGEM
}

Por

Karina Riccio Ribeiro

ORIENTADOR: Lauro da Gama e Souza Júnior

2019.1

PONTIFÍCIA UNIVERSIDADE CATÓLICA DO RIO DE JANEIRO

RUA MARQUÊS DE SÃO VICENTE, 225 - CEP 22451-900

RIO DE JANEIRO - BRASIL 


\title{
A IMPUGNAÇÃO DO ÁRBITRO SEGUNDO O ESTÁGIO DA ARBITRAGEM
}

\author{
por \\ Karina Riccio Ribeiro
}

Monografia apresentada ao
Departamento de Direito da
Pontificia Universidade Católica do
Rio de Janeiro (PUC-Rio) para a
obtenção do Título de Bacharel em
Direito.

Orientador: Lauro da Gama e Souza Júnior

2019.1 


\section{AGRADECIMENTOS}

Após tanto estudo sobre o Dever de Revelar, aproveito essas breves páginas para agradecer aqueles que me fazem - felizmente - deixar de lado a independência.

Agradeço aos meus pais, Monica e Ricardo, por todo o incentivo que sempre me deram, por cada vez que nos colocaram em primeiro lugar, pela dedicação e pelos incontáveis momentos bons. Obrigada por entenderem e apoiarem a pessoa que sou, com todos os desejos e também os desesperos com coisas desnecessárias. Ao meu irmão, Raphael, por partilhar a vida comigo, pela parceria em casa, em viagens e em aprontar. Obrigada pelas noites de palhaçada e de invasão no meu quarto enquanto eu tentava estudar.

Ao Lauro Gama, meu orientador, chefe e inspiração, por ter acreditado em mim. Agradeço por cada ensinamento, na PUC, no escritório e na vida. Obrigada por mostrar que, para fazermos as coisas darem certo, precisamos continuar com humildade, sem nunca perder o bom humor.

Aos amigos de infância, Carolina Mello, Isabelle Rocha, Lays Santos, Matheus Suknaic Natália Gautreaux, Natália Morrissy, Nicole Lopes e Priscila Nery. Foi leve crescer com vocês, partilhar escola, viagens e as descobertas de adolescente e da "vida adulta". Obrigada por entenderem a vida nova, de prazos, provas e noites no escritório, e por, mesmo com isso tudo, estarem sempre lá para mim.

Uma vez me disseram que o problema da PUC é que não tem turma e, assim, ficamos muitas vezes "soltos", com um mesmo grupinho que nem sempre estaria na sala com você. Discordo. A PUC não ter turma nos faz criar ainda mais laços do que o normal, a cada aula fazemos amigos diferentes que, talvez, nem teríamos conhecido se estivéssemos condicionados ao padrão 
“turma”. Agradeço, então, a cada uma das pessoas dos meus grupinhos, aos amigos avulsos e mesmo assim tão importantes, às amizades que nasceram nos Jogos Jurídicos e que duraram para sempre, aos amigos de PIBIC e àqueles que não sei nem mesmo explicar como chegaram na minha vida, apesar de ter certeza de que não os deixarei sair. Se a faculdade foi incrível, mesmo em momentos de $\mathrm{OAB}$, monografia e essas coisas que tiraram nosso sono e se eu tive prazer em ir à PUC até o último dia de aula desses 5 anos, foi graças a vocês.

Agradeço à família que ganhei no Binenbojm, Gama \& Carvalho Britto. Sim, família. Porque é a família que compartilha todas as coisas boas e ruins, que comemora junto cada vitória e que também são o porto seguro para dias ruins. E confesso que não sei no que somos melhores, se em comemorar, seja no bar, na festa ou em uma viagem, ou em ser porto seguro e dar um jeito de resolver qualquer pedra gigante que a vida coloca em nosso caminho. Obrigada por me mostrarem que podemos, juntos, levar o caos para qualquer lugar. Obrigada por me darem o prazer de ser Totozinha, certamente uma das melhores partes de mim.

Aos amigos do Lauro Gama Advogados agradeço pelo amadurecimento. Foi lá que, finalmente, me vi adulta. E foram vocês que tiveram que aturar e conviver com essa mudança (acho que, além de agradecer, também preciso pedir desculpas por isso). Obrigada por cada troca que tivemos, pelos momentos de descontração e de seriedade, por cada almoço, lanche da tarde e conversas diárias. 


\section{RESUMO}

RIBEIRO, Karina Riccio. A impugnação do Árbitro segundo o estágio da Arbitragem. Rio de Janeiro: 2019: 63 p. Monografia de final de curso. Departamento de Direito da Pontifícia Universidade Católica do Rio de Janeiro - PUC-Rio.

O presente trabalho pretende analisar o impacto da impugnação do Árbitro em três diferentes estágios do procedimento arbitral, aqui delimitados como: (i) antes da assinatura do Termo de Arbitragem; (ii) durante o curso do procedimento, isto é, entre a assinatura do Termo de Arbitragem e a prolação da Sentença Arbitral Final; e (iii) no período após a prolação da Sentença Arbitral Final e antes do fim do prazo para a Decisão sobre Pedidos de Esclarecimentos. Nele serão analisados os conceitos mais íntimos do processo de impugnação, bem como os Regulamentos e disposições sobre o tema. Por fim, avaliar-se-á os impactos da impugnação dos Árbitros em cada um dos estágios do procedimento arbitral.

Palavras-Chave: Arbitragem; Impugnação; Independência; Imparcialidade; Dever de Revelação; Dever de Investigação. 


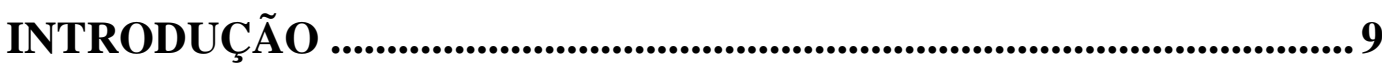

CAPÍTULO 1 - A Impugnação pelas Partes e seus critérios gerais..... 12

1.1. Independência e Imparcialidade ……………………………...... 12

1.2. Dever de Revelação ...................................................................... 16

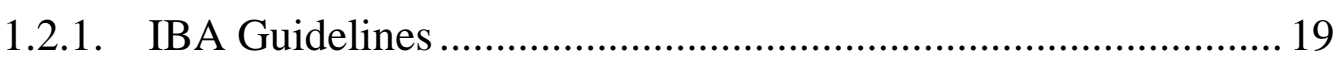

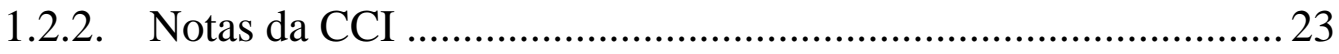

1.3 Dever de Investigação das Partes................................................. 25

CAPÍTULO 2 - Questões relacionadas ao momento da Impugnação 27

2.1. Impugnação no Início do Procedimento Arbitral ......................... 28

2.2. Impugnação no Curso do Procedimento Arbitral......................... 31

2.3. Impugnação Depois da Sentença Arbitral Final............................ 35

CAPÍTULO 3 - Análise de casos ..................................................................37

3.1. Caso $n^{\circ} 1$ de Impugnação no Início do Procedimento................... 37

3.1.1. Fundamentos da Impugnação ………………………………...... 37

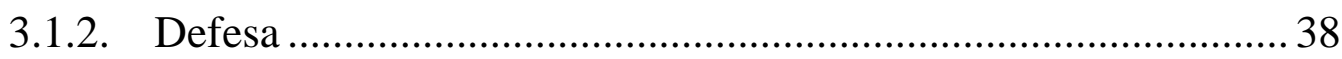

3.1.3. Decisão sobre a Impugnação ....................................................... 39

3.2. Caso $n^{\circ} 2$ de Impugnação no Início do Procedimento ................... 41

3.2.1. Fundamentos da Impugnação ....................................................... 41

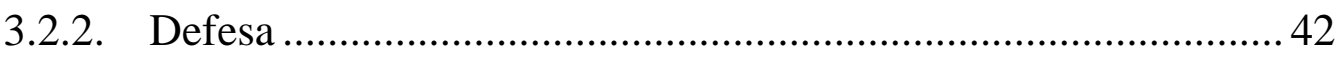

3.2.3. Decisão sobre a Impugnação .................................................... 43

3.3 Caso $n^{\circ} 1$ de Impugnação no Curso do Procedimento ..................... 43

3.3.1. Fundamentos da Impugnação ...................................................... 43

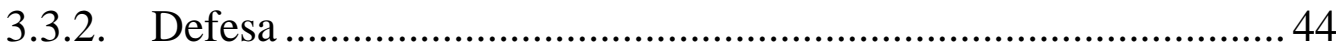

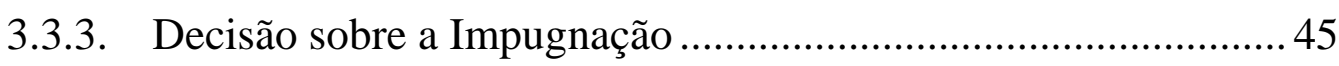

3.4. Caso $n^{\circ} 2$ de Impugnação no Curso do Procedimento ……….... 46

3.4.1. Fundamentos da Impugnação ...................................................... 46

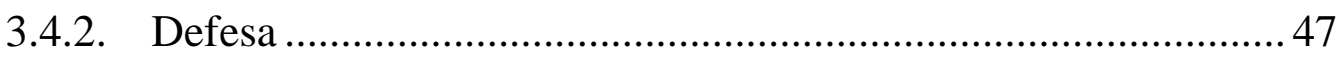

3.4.3. Decisão sobre a Impugnação ...................................................... 48 
3.5. Caso $n^{\circ} 1$ de Impugnação após a Sentença ........................................ 48

3.5.1. Fundamentos da Impugnação .................................................... 49

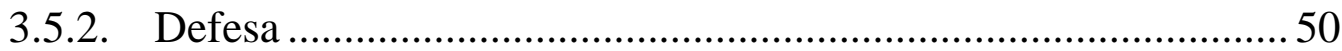

3.5.3. Decisão sobre a Impugnação ..................................................... 52

3.6. Caso $\mathrm{n}^{\mathrm{o}} 2$ de Impugnação após a Sentença ......................................53

3.6.1. Fundamentos da Impugnação ………………………………......53

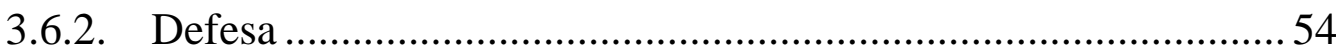

3.6.3. Decisão sobre a Impugnação .................................................... 54

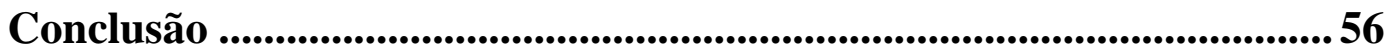

REFERÊNCIAS BIBLIOGRÁFICAS ................................................59 


\section{LISTA DE ABREVIAÇÕES}

Art./Arts. - Artigo/Artigos

CAMARB - Câmara de Arbitragem Empresarial-Brasil

CAM-CCBC - Centro de Arbitragem e Mediação da Câmara de Comércio Brasil-Canadá

CCI - Corte Internacional de Arbitragem da Câmara de Comércio Internacional

IBA - International Bar Association

IBA Guidelines - Diretrizes da IBA relativas a Conflitos de Interesses em Arbitragem Internacional

LArb/Lei de Arbitragem - Lei ${ }^{\circ}$ 9.307, de 23 de setembro de 1996, com as modificações da Lei $\mathrm{n}^{\circ} 13.129$ de 26 de maio de 2015

Lei Modelo/Lei Modelo da UNCITRAL - Lei Modelo da UNCITRAL sobre Arbitragem Comercial Internacional de 1985, com alterações adotadas em 2006

LCIA - The London Court of International Arbitration

Notas da CCI - Notas às Partes e aos Tribunais Arbitrais sobre a Condução da Arbitragem Conforme o Regulamento de Arbitragem da CCI

P./pp./Págs. - Página/Páginas

Partes - Requerente e Requerida/o

Regulamento CAM-CCBC - Regulamento de Arbitragem do CAM-CCBC, de $1^{\circ}$ de setembro de 2011, com alterações aprovadas em 28 de abril de 2016

Regulamento CAMARB - Regulamento de Arbitragem da CAMARB, de setembro de 2017

Regulamento CCI - Regulamento de Arbitragem da CCI, em vigor a partir de $1^{\circ}$ de março de 2017

Regulamento LCIA - Regulamento de Arbitragem da LCIA de $1^{\circ}$ de outubro de 2014

Sentença - Sentença Arbitral Final 
Termo - Termo de Arbitragem

UNCITRAL - United Nations Commission on International Trade Law

$\S / \S \S$ - Parágrafo/Parágrafos 


\section{INTRODUÇÃO}

A consolidação da Arbitragem no Brasil como método de solução de conflitos trouxe consigo questões mais complexas e sensíveis. Dentre tais questões destaca-se a confiança no fato de que o árbitro indicado para aquele procedimento atuará de forma equidistante entre as Partes, sendo necessário, para tanto, que cumpra seus deveres de independência e imparcialidade previstos no art. $13, \S 6^{\circ}$ da Lei de Arbitragem ${ }^{1}$.

Para garantir a observância da independência e imparcialidade do Árbitro quando da condução e do julgamento do litígio, existem mecanismos amplamente consolidados na prática arbitral. O primeiro mecanismo costuma ser adotado pelas próprias Câmaras, através do envio, para o Árbitro, de formulários de independência e imparcialidade, quando do aceite da indicação. Há, ainda, a possibilidade de impugnação pelas Partes a qualquer momento do procedimento, caso existam indícios de que o Árbitro não agiu de forma independente e imparcial. Nos casos em que tais questões não são resolvidas ou descobertas no curso do procedimento, pode-se recorrer à anulação do Laudo Arbitral pelo Poder Judiciário.

Em que pese a existência de todos esses métodos, este trabalho se concentrará no estudo das Impugnações, analisando, para tanto, princípios a ela relacionados e suas formas de aplicação segundo Regulamentos de Câmaras nacionais e internacionais. Ainda que a independência, a imparcialidade e o dever de revelar sejam realidade de qualquer Árbitro, o trabalho restringe-se à análise de impugnações em Arbitragens institucionais, desconsiderados, portanto, os procedimentos Ad Hoc. Tal delimitação no escopo desse trabalho foi feita pelo anseio de se conseguir identificar melhor os padrões e critérios em comum que as Câmaras Arbitrais apresentam para

\footnotetext{
${ }^{1}$ Lei de Arbitragem, Art. 13, $\S 6^{\circ}$ : No desempenho de sua função, o árbitro deverá proceder com imparcialidade, independência, competência, diligência e discrição.
} 
a impugnação do Árbitro. Pelo caráter mais peculiar e sui generis do procedimento $A d H o c$, essa análise ficaria prejudicada.

Foram delimitados, ainda, os três principais momentos, aqui denominados como estágios, em que a impugnação pode se dar. São eles: (i) quando da indicação do Árbitro, ou seja, antes da assinatura do Termo de Arbitragem; (ii) durante o curso do procedimento, isto é, entre a assinatura do Termo de Arbitragem e a prolação da Sentença Arbitral Final; e (iii) no período compreendido entre a prolação da Sentença Arbitral Final e o fim do prazo para a Decisão sobre Pedidos de Esclarecimentos.

Estabelecidas tais premissas, buscou-se, a partir da análise doutrinária e jurisprudencial, entender os impactos e consequências das impugnações em cada uma das três fases acima apontadas, observando, para tanto, o quanto o marco temporal influencia na decisão de aceitar ou não o afastamento do Árbitro daquele Procedimento Arbitral.

A fim de cumprir esse objetivo de maneira didática e organizada, este trabalho foi dividido em três capítulos. O Capítulo 1 (A Impugnação pelas Partes e seus critérios gerais) apresenta os conceitos básicos de independência e imparcialidade, destacando suas diferenças e relevâncias para o pedido de Impugnação do Árbitro. O Capítulo revela ainda dois mecanismos que buscam diminuir a quantidade de pedidos de Impugnação, que são, por parte do Árbitro, o dever de revelação e, por parte das Partes, o dever de Investigação.

Delimitados tais conceitos, passa-se a analisar as questões específicas relacionadas ao momento da Impugnação (Capítulo 2). Nessa etapa, além de temas e características representativas da impugnação no início do procedimento arbitral, no curso do procedimento arbitral e depois da prolação da Sentença Final, serão analisados também Regulamentos de Câmaras 
nacionais e internacionais, estabelecendo semelhanças e diferenças entre eles.

Por fim, o Capítulo 3 ocupa-se da análise de casos de impugnação nos diferentes estágios da arbitragem e sob o regimento de Regulamentos de Câmaras distintas (CCBC, CCI e LCIA). São apresentadas, em relação a cada um dos casos estudados, a causa da Impugnação suscitada pela Parte, a defesa realizada pelo Árbitro impugnado e, por fim, a decisão de deferimento ou não do Pedido de Impugnação. 


\section{CAPÍTULO 1 - A IMPUGNAÇÃO PELAS PARTES E SEUS CRITÉRIOS GERAIS}

\subsection{Independência e Imparcialidade}

A independência e a imparcialidade são deveres basilares dos Árbitros e estão previstos nos arts. $13, \S 6^{\circ}$ e $21, \S 2^{\circ}$ da Lei de Arbitragem, na forma que se segue:

Art. 13. Pode ser árbitro qualquer pessoa capaz e que tenha a confiança das partes. (...) $\S 6^{\circ}$ No desempenho de sua função, o árbitro deverá proceder com imparcialidade, independência, competência, diligência e discrição.

Art. 21. A arbitragem obedecerá ao procedimento estabelecido pelas partes na convenção de arbitragem, que poderá reportar-se às regras de um órgão arbitral institucional ou entidade especializada, facultando-se, ainda, às partes delegar ao próprio árbitro, ou ao tribunal arbitral, regular o procedimento. (...) $\S 2^{\circ}$ Serão, sempre, respeitados no procedimento arbitral os princípios do contraditório, da igualdade das partes, da imparcialidade do árbitro e de seu livre convencimento.

A fim de melhor analisar o tema, importa estabelecer de forma clara o significado de cada um desses deveres. Para tanto, pode-se definir o dever de independência como aquele que permite ao Árbitro criar, exclusivamente a partir daquilo que lhe é posto pelas Partes ao longo do procedimento, seu livre convencimento ${ }^{2}$. Nas palavras de Adriana Noemi Pucci:

A postura independente do árbitro frente às partes traduz-se na inexistência de qualquer relação ou vínculo deste com aquelas ou com alguma pessoa estritamente vinculada a elas, sejam essas relações ou vínculos de caráter pessoal, social, econômico, financeiro ou de qualquer outra natureza. ${ }^{3}$

Em relação à independência, é essencial o entendimento de que esta deve ser determinada a partir da perspectiva das Partes, motivo pelo qual

\footnotetext{
${ }^{2}$ PUCCI, Adriana Noemi. Impugnação de Árbitros. In: CARMONA, Carlos Alberto, LEMES, Selma Ferreira e MARTINS, Pedro BATISTA. 20 anos da lei de arbitragem: Homenagem a Petrônio R. Muniz. São Paulo: Atlas, 2017, p.176.

${ }^{3}$ PUCCI, Adriana Noemi. O árbitro na arbitragem internacional. Princípios éticos. Arbitragem comercial internacional (Coord.). São Paulo: LTr, 1998. P. 121.
} 
deve o Árbitro revelar aqueles fatos que, no entendimento das Partes, possam vir a pôr em risco sua independência.

A imparcialidade, por sua vez, residiria na abstenção, por parte do Árbitro, de uma inclinação pré consolidada em decidir de acordo com a tese apresentada por uma das Partes ${ }^{4}$. Há, aqui, uma tentativa de impedir que se revele um verdadeiro interesse do Árbitro na solução do conflito ${ }^{5}$.

Todavia, é importante lembrar que, na maioria das vezes, as Partes indicam os Árbitros levando em consideração sua proximidade e relação com o tema, além de seu posicionamento consolidado acerca da questão que está sendo discutida ${ }^{6}$. É de se esperar, portanto, que o Árbitro já tenha um determinado entendimento sobre o tema ${ }^{7}$. Quando dentro de um nível razoável, não pode ser assumido como uma violação ao dever de imparcialidade ${ }^{8}$.

\footnotetext{
${ }^{4}$ LUCON, Paulo Henrique dos Santos. Imparcialidade na arbitragem e impugnação aos árbitros. Revista de Arbitragem e Mediação. Out-Dez 2013, vol. 39/2013, p. 39.

${ }^{5}$ LEMES, Selma Maria Ferreira. O Procedimento de Impugnação e Recusa de Árbitro, como sistema de controle quanto à independência e a imparcialidade do julgador. Revista de Arbitragem e Mediação, Jul-Set 2016, vol. 50/2016, versão digital.

6 "Challenges for lack of impartiality may also be based on prior academic writings (e.g. in article or books) in which the arbitrator has taken a position that is contrary to an aspect of the challenging party's case. Such challenges have virtually never succeeded. Challenges based on an arbitrator's relationship with a subject matter (issue conflicts) are less likely to succeed in commercial arbitration, where the issues in dispute are more likely to turn on facts and circumstances unique to the case and the contract, than in investment treaty arbitration, where similar and related issues often arise." (FRY, Jason; GREENBERG, Simon e MAZZA, Francesca. The Secretariat's Guide to ICC Arbitration: A Practical Commentary on the 2012 ICC Rules of Arbitration from the Secretariat of the ICC International Court of Arbitration. Paris: International Chamber of Commerce (ICC), 2012, p. 172)

7 “Tais noções, meramente escolares, não auxiliam na solução de problemas concretos, pois: (...) (ii) o conceito de equidistância, utilizado sem grandes problemas para caracterizar o juiz (funcionário estatal investido de poderes antes da ocorrência da disputa e sorteado para resolvê-la), não pode ser utilizado para o árbitro, que é escolhido justamente por suas características pessoais e/ou seus contatos profissionais ou acadêmicos com os advogados da causa, hábeis a ensejar a confiança de ao menos uma das partes; (iii) a imparcialidade, por ser um fenômeno psíquico, jamais poderia ser aferida in natura, necessitando de uma manifestação fática para ser detectada; e (iv) todo e qualquer julgador é sempre influenciado por circunstâncias outras que não somente o mérito da causa, uma vez que sua própria interpretação do objeto litigioso depende, entre outros, de sua instrução ou formação acadêmica, orientação política e ideológica, posição econômica, nacionalidade e de todas as preferências (e repúdios) inalienáveis de cada ser humano." (ELIAS, Carlos. O Árbitro. In: LEVY, Daniel e PEREIRA, Guilherme Setoguti J. (Coords.). Curso de Arbitragem. São Paulo: Thomson Reuters Brasil, 2018. P. 150)

${ }^{8}$ CASEY, J. Brian. Selection of the Tribunal. In: HANESSIAN, Grant e NEWMAN, Lawrence W. (Ed.). International Arbitration Checklists, Second Edition. New York: JurisNet, LLC, 2009. P. 44.
} 
O que não pode acontecer é o Árbitro não dar às Partes a possibilidade de lhe mostrar um entendimento diverso daquele pré-concebido acerca do tema ${ }^{9}$. Ou seja, pode-se ter um posicionamento sobre o assunto que permeia o litígio, mas não sobre sua aplicação prática naquele litígio ao qual foi indicado para solucionar. ${ }^{10}$

Acresce-se à essas definições mais cruas a ideia de que podemos tratar a independência como um conceito mais objetivo, por estar relacionado a questões fáticas, como a relação entre todos os envolvidos no procedimento $^{11}$. A imparcialidade, por outro lado, é subjetiva, já que referente à crenças e entendimentos intelectuais do Árbitro ${ }^{12}$.

Exatamente por seu caráter subjetivo, parte da doutrina entende que a imparcialidade é mais difícil de ser comprovada pela Parte impugnante ${ }^{13}$. Isso porque, se não houver um laço forte entre a Parte e o Árbitro, ou ainda entre o Árbitro e o objeto do litígio, será mais custoso apresentar provas que coloquem em dúvida sua parcialidade ${ }^{14}$.

\footnotetext{
${ }^{9}$ ELIAS, Carlos. O Árbitro. In: LEVY, Daniel e PEREIRA, Guilherme Setoguti J. (Coords.). Curso de Arbitragem. São Paulo: Thomson Reuters Brasil, 2018. P. 151.

${ }^{10}$ PUCCI, Adriana Noemi. Impugnação de Árbitros. In: CARMONA, Carlos Alberto, LEMES, Selma Ferreira e MARTINS, Pedro BATISTA. 20 anos da lei de arbitragem: Homenagem a Petrônio R. Muniz, São Paulo: Atlas, 2017, p. 175.

${ }^{11}$ LEE, João Bosco e PROCOPIAK, Maria Cláudia de Assis. A Obrigação de Revelação do Árbitro - Está influenciada por Aspectos Culturais ou Existe um Verdadeiro Standard Universal? Revista Brasileira de Arbitragem, 2007, vol. IV, issue 14, versão digital.

${ }^{12}$ Nas palavras de Thomas Clay: "On peut cependant observer que dans cette abondante doctrine se dégage un critère qui est accepté par une majorité - relative - d'auteurs pour distinguer l'indépendence de l'imparcialité : la première serait avant tout une donné objective, alors que la seconde serait essentiellement subjective. La première s'apprécierait par rapport à des liens factuels, et la seconde en fonction de prédispositions intellectuelles." (CLAY, Thomas. L'Arbitre. Paris: Dalloz, 2001.P.246).

13 "A challenge based purely on an alleged lack of impartiality is generally more difficult to make. Such challenges are most commonly grounded on what a party perceives as unfair treatment in the proceedings or on an arbitrator's conduct or comments during a hearing or meeting. Challenges based purely on an arbitrator's procedural decisions have very rarely succeeded." (FRY, Jason; GREENBERG, Simon e MAZZA, Francesca. The Secretariat's Guide to ICC Arbitration: A Practical Commentary on the 2012 ICC Rules of Arbitration from the Secretariat of the ICC International Court of Arbitration. Paris: International Chamber of Commerce (ICC), 2012, p. 172.) ${ }^{14}$ Nesse sentido, Luiz Olavo Baptista: "A imparcialidade é um sentimento subjetivo da pessoa, a independência decorre de fatores externos, sendo mais facilmente detectável." (BAPTISTA, Luiz Olavo. Arbitragem comercial e internacional. São Paulo: Lex Editora, 2011. p. 165. Ver também: CASEY, J. Brian. Selection of the Tribunal. In: HANESSIAN, Grant e NEWMAN, Lawrence W. (Ed.). International Arbitration Checklists, Second Edition. New York: JurisNet, LLC, 2009. P. 44.
} 
A fim de facilitar a identificação das situações caracterizadoras da parcialidade do Árbitro, Carlos Elias propõe a análise de dois grupos de critérios ${ }^{15}$.

O primeiro grupo, que aqui será usado para a identificação de casos de violação ao dever de independência ${ }^{16}$, engloba (i) a proximidade entre o Árbitro e a Parte ou pessoas e entidades a eles relacionadas; (ii) a intensidade dessa relação; (iii) a frequência e a duração dos contatos entre Árbitro e Partes; e, por fim, (iv) a contemporaneidade da relação ${ }^{17}$.

Já o segundo grupo, que versa sobre imparcialidade, apresenta os seguintes critérios de atenção:

(i) o contato ou atuação anteriores do árbitro com a matéria objeto do litígio; (ii) o fato de o árbitro ter que decidir matéria idêntica ou muito parecida com aquela que ele tem que defender em outra causa; (iii) a existência de manifestação do árbitro (incluindo produção acadêmica) sobre a causa ou circunstâncias fático-jurídicas idênticas àquelas que deve analisar; ou (iv) o árbitro ser alvo de constantes indicações pela parte ou pelo escritório que a patrocina ${ }^{18}$.

Do exposto, pode-se concluir que a identificação e a caracterização de um fato que envolva algum ato, relação ou pronunciamento do Árbitro como fator que ponha em risco sua independência ou imparcialidade é algo extremamente sensível ${ }^{19}$. Isso porque, não cabe apenas a análise do fato em

\footnotetext{
${ }^{15}$ ELIAS, Carlos. O Árbitro. In: LEVY, Daniel e PEREIRA, Guilherme Setoguti J. (Coords.). Curso de Arbitragem. São Paulo: Thomson Reuters Brasil, 2018.p. 153.

${ }^{16}$ Pede-se vênia ao ilustre autor para separar o primeiro grupo de critérios e alocá-lo com as hipóteses de independência. Tal modificação é necessária a este trabalho para harmonizar as situações com o conceito de independência acima definido.

${ }^{17}$ ELIAS, Carlos. O Árbitro. In: LEVY, Daniel e PEREIRA, Guilherme Setoguti J. (Coords.). Curso de Arbitragem. São Paulo: Thomson Reuters Brasil, 2018.p. 153.

${ }^{18}$ ELIAS, Carlos. O Árbitro. In: LEVY, Daniel e PEREIRA, Guilherme Setoguti J. (Coords.). Curso de Arbitragem. São Paulo: Thomson Reuters Brasil, 2018. P. 154.

${ }^{19}$ Nas lições de Fouchard, Gaillard e Goldman: "It is not easy to provide a comprehensive definition of the qualities of independence and impartiality required of arbitrators. Independence is a situation of fact or law, capable of objective verification. Impartiality, on the other hand, is more a mental state, which will necessarily be subjective. Impartiality is of course the essential quality required of a judge. However, as it is rarely possible to provide direct proof of impartiality, the arbitrators should at least be required to be independent, which is easier to prove and which, in principle, guarantees the arbitrator's freedom of judgment." (GAILLARD, Emmanuel e SAVAGE, Jonhn (Ed.). Fouchard, Gaillard, Goldman on International Commercial Arbitration, vol. I. Londres: Wolters Kluwer, 1999, p.564)
} 
si, ela deve ainda ser agregada ao entendimento que as Partes têm sobre o ocorrido visto que, em última análise, é delas que se espera a confiança no Árbitro.

E essa confiança, vale ressaltar, é esperada em todas as fases do procedimento arbitral, já acima elencadas como: (i) quando da indicação do Árbitro, ou seja, antes da assinatura do Termo de Arbitragem; (ii) durante o curso do procedimento, isto é, entre a assinatura do Termo de Arbitragem e a prolação da Sentença Arbitral Final; e (iii) no período compreendido entre a prolação da Sentença Arbitral Final e o fim do prazo para a Decisão sobre Pedidos de Esclarecimentos. É o que define o Princípio Geral das IBA Guidelines ${ }^{20}$ :

(1) Princípio Geral: Todo árbitro deve ser imparcial e independente em relação às partes ao aceitar sua nomeação, e assim permanecer durante todo o processo arbitral até que prolatada a sentença final ou de outra forma extinto o processo em caráter definitivo.

A partir do entendimento da distinção entre independência e imparcialidade, que, apesar de diversas, estão intimamente relacionadas, pode-se dar continuidade à análise dos critérios gerais da impugnação com o estudo sobre o dever de Revelação.

\subsection{Dever de Revelação}

O dever de revelação está previsto na Lei de Arbitragem da seguinte forma:

Art. 14. Estão impedidos de funcionar como árbitros as pessoas que tenham, com as partes ou com o litígio que lhes for submetido, algumas das relações que caracterizam os casos de impedimento ou suspeição de juízes, aplicando-se-lhes, no que couber, os mesmos deveres e responsabilidades, conforme previsto no Código de Processo Civil.(...) $§ 1^{\circ}$ As pessoas indicadas para funcionar como

\footnotetext{
${ }^{20}$ Tratando-se de instrumento de soft law, tais dispositivos são não-vinculante mas poderão orientar, como diretrizes, os Tribunais e Câmaras Arbitrais.
} 
árbitro têm o dever de revelar, antes da aceitação da função, qualquer fato que denote dúvida justificada quanto à sua imparcialidade e independência.

No entendimento da melhor doutrina, o dever de revelar tem a função de possibilitar às Partes que, a partir das informações reveladas pelo Árbitro, possam analisar tudo aquilo que entendem prejudicar a imparcialidade e independência do julgador e, em seguida, reiterar ou revogar sua confiança no Árbitro indicado ${ }^{21}$. O dever de revelar, portanto, é de extrema importância uma vez que não cabe ao Árbitro decidir sozinho sobre seu nível de independência ou imparcialidade ${ }^{22}$.

Além disso, há ainda os autores que classificam o dever de revelar como essencialmente contratual pois permite que as Partes tomem conhecimento dos fatos que podem, potencialmente, desqualificar o Árbitro indicado ${ }^{23}$.

Importante ressaltar, também, que o dever de revelar é atemporal, ou seja, ele não está adstrito apenas ao primeiro estágio do procedimento arbitral, da indicação do Árbitro. Por este motivo, o dever de revelar deve perdurar até o final do procedimento, com a prolação da Decisão sobre Pedidos de Esclarecimentos ${ }^{24}$.

\footnotetext{
${ }^{21} \mathrm{Na}$ doutrina italiana: "Per duty of disclosure si intende l'obbligo previsto in capo agli arbitri da molti ordinamenti stranieri e dal regolamento di diverse istituzioni arbitrali organizzate nazionali ed internazionali, di rendere edotte le parti di tutti i fatti, esistenti al momento della nomina o sopravvenuti nel corso del giudizio, astrattamente idonei a ridurne l'imparcialità o giustificarne la ricusazione." (BENEDETTELLI, Massimo V., CONSOLO, Claudio e RADICATI DI BROZOLO, Luca. Commentario breve al diritto dell'arbitrato nazionale ed internazionale. Milão: Casa Editrice Dott. Antonio Milani, 2010, pp. 163 e 164). Na doutrina nacional: MARQUES, Ricardo Dalmaso. Breves Apontamentos sobre a Extensão do Dever de Revelação do Árbitro. Revista Brasileira de Arbitragem, 2011, vol. VIII, issue 31, p. 65.

${ }^{22}$ FERRO, Marcelo Roberto. Apontamentos sobre a independência dos árbitros. In: ADAMEK, Marcelo Vieira Von (Ed.). Temas de direito societário e empresarial contemporâneos. São Paulo: Malheiros, 2011, p. 858.

${ }^{23}$ ELIAS, Carlos. O Árbitro. In: LEVY, Daniel e PEREIRA, Guilherme Setoguti J. (Coords.). Curso de Arbitragem. São Paulo: Thomson Reuters Brasil, 2018. P. 156.

${ }^{24}$ Nas palavras de Carlos Alberto Carmona: "O dever de revelação é considerado contínuo durante todo o procedimento arbitral: se houver fatos novos surgidos e que o árbitro julgue dignos de nota, deve comunicar às partes, até porque pode dar-se o caso de descobrir o árbitro, depois de iniciados os procedimentos, que estaria ligado indiretamente a uma das partes (suponha-se que descubra ter havido relacionamento comercial importante de empresa que tenha dirigido com uma das partes, ou que tenha prestado serviços a uma empresa que descubra estar ligada por laços societários a uma
} 
Fato é que, após a apreciação das Partes de determinado fato revelado (durante qualquer momento do procedimento), caso as Partes aceitem a continuidade do Árbitro na condução do procedimento arbitral, elas perdem o direito de impugnar o Árbitro em face de tal questão ${ }^{25}$. A exceção a esse entendimento ocorre apenas quando restar comprovado que o Árbitro, ao realizar sua revelação, não a fez da maneira mais adequada e transparente possível, omitindo, ou mesmo alterando determinadas situações relacionadas ao que fora revelado.

Já sobre a extensão do dever de revelar, pode-se dizer que o Árbitro precisa expor não apenas aqueles fatos mais marcantes, dos quais rapidamente se recorda. Cabe a ele realizar uma pesquisa apurada da relação de seu escritório com as Partes, seus Patronos e, ainda, empresas a elas coligadas, como, por exemplo, subsidiárias ${ }^{26}$.

Nesse contexto, toda vez que incorrer em dúvidas sobre se deve ou não revelar determinado fato, é recomendável fazê- $1 \mathrm{l}^{27}$. Tal entendimento ocorre a partir da ponderação entre os benefícios decorrentes da revelação de um fato que pode em nada significar para as Partes, e os prejuízos de se omitir um fato que possa vir a ser relevante ${ }^{28}$.

\footnotetext{
das partes contendentes)." (CARMONA, Carlos Alberto. Arbitragem e processo: um comentário à Lei $n^{\circ}$ 9.307/96. 3 ed. rev., atual. e ampl. São Paulo: Atlas, 2009, p. 254.)

${ }^{25}$ MARQUES, Ricardo Dalmaso. Breves Apontamentos sobre a Extensão do Dever de Revelação do Árbitro. Revista Brasileira de Arbitragem, 2011, vol. VIII, issue 31, p. 66.

${ }^{26}$ Notas às Partes e aos Tribunais Arbitrais sobre a Condução da Arbitragem conforme o Regulamento de Arbitragem da CCI, $1^{\circ}$ de janeiro de 2019, §27.

${ }_{27}$ PUCCI, Adriana Noemi. Impugnação de Árbitros. In: CARMONA, Carlos Alberto, LEMES, Selma Ferreira e MARTINS, Pedro BATISTA. 20 anos da lei de arbitragem: Homenagem a Petrônio R. Muniz, São Paulo: Atlas, 2017, p. 177. A mesma recomendação é dada pelo Princípio Gera $\mathrm{n}^{\mathrm{o}} 3$, (c) das IBA Guidelines, como se segue: “(c) Eventual dúvida quanto à necessidade de divulgação de determinados fatos ou circunstâncias por um árbitro deve ser dirimida em favor da divulgação." (Diretrizes da IBA relativas a Conflitos de Interesses em Arbitragem Internacional. Londres: International Bar Association, 2004.)

${ }^{28}$ LEMES, Selma Maria Ferreira. A Independência e a Imparcialidade do Árbitro e o Dever de Revelação. Revista Brasileira de Arbitragem, 2010, vol. VII, issue 26, p. 27.
} 
Como resultado da análise do instituto do dever de revelar, depreendese que, além de dar às Partes a oportunidade de tomarem conhecimento e, com isso, decidir acerca da impugnação ou não do Árbitro indicado, ele protege, sobretudo, o Árbitro. Isso porque, ao revelar às Partes tudo aquilo que poderia ser prejudicial à sua independência ou imparcialidade para o julgamento do litígio, ele não só fortalece a confiança que as Partes têm sobre seu trabalho, como também transfere a elas o ônus de ponderar e decidir a gravidade daquilo que lhes fora revelado ${ }^{29}$.

\subsubsection{IBA Guidelines}

Com o aumento das relações pessoais gerada pela advocacia internacional e um maior campo de atuação dos grandes escritórios, a comunidade arbitral vivenciou o crescimento da necessidade de revelações, que apresentavam questões cada vez mais complexas ${ }^{30}$.

Foi diante desse cenário que a International Bar Association formou um Grupo de Trabalho com o objetivo de, a partir da análise prática de como cada país, cada ordenamento jurídico, lida com as questões de independência, imparcialidade e dever de revelação. Com base nessa análise, os especialistas do Grupo de Trabalho prepararam as Diretrizes da IBA, ou IBA Guidelines, que serviriam para facilitar ao Árbitro a avalição do que deve ou não ser revelado ${ }^{31}$.

\footnotetext{
${ }^{29}$ Os benefícios do dever de revelar são assim expostos por Thomas Clay: "L'obligation pour l'arbitre de révéler les liens qui unissent aux parties est à la fois la plus élémentire précaution qu'on peut attendre de lui et en même temps la plus essentielle, car c'est celle par laquelle un arbitre alertera les parties sur les risques d'atteinte à son indépendance, et ce faisant immunisera l'instance arbitrale contre toute action postérieure qui viserait ces risques acceptés. C'est aussi un signe de son irréprochable probité. La revélation est, en quelque sorte, l' «assurance-vie» de l'instance arbitrale". (CLAY, Thomas. L'Arbitre. Paris: Dalloz, 2001, p. 318)

${ }^{30}$ Diretrizes da IBA relativas a Conflitos de Interesses em Arbitragem Internacional. Londres: International Bar Association, 2004, §1.

${ }^{31}$ Diretrizes da IBA relativas a Conflitos de Interesses em Arbitragem Internacional. Londres: International Bar Association, 2004, $\S \S 3$ e 4. Para um maior detalhamento sobre o processo de elaboração das IBA Guidelines, confira-se: PROCOPIAK, Maria Cláudia de Assis. As diretrizes do International Bar Association sobre Conflitos de Interesses na Arbitragem Internacional. Revista Brasileira de Arbitragem, 2007, vol. IV, issue 16, pp. 7-40.
} 
A estrutura das IBA Guidelines é dividida em dois blocos principais. O primeiro bloco refere-se aos princípios gerais relativos a imparcialidade, independência e divulgação. Dentre eles, há a definição e algumas regras gerais sobre: (i) Conflito de Interesse; (ii) Divulgação pelo Árbitro; (iii) Renúncia pelas Partes; (iv) Escopo das Guidelines; (v) Relacionamentos; e, por fim, (vi) Atribuições do Árbitro e das Partes.

O segundo bloco, por sua vez, trata da aplicação prática dos Princípios Gerais apresentados no bloco anterior. Nesse agrupamento, o Grupo de Trabalho buscou estabelecer situações reais que os Árbitros normalmente enfrentam e as dividiu em 3 principais listas (Vermelha, Laranja e Verde) ${ }^{32}$.

A Lista Vermelha compreende ainda uma subdivisão entre Lista Vermelha Irrenunciável e Lista Vermelha Renunciável. A primeira é composta por aquelas situações que, se existentes, impedem completamente o Árbitro de atuar naquele procedimento, devendo, assim, renunciar de pronto. Já a Lista Vermelha Renunciável apresenta casos sérios, mas não tão graves quanto a Lista Vermelha Irrenunciável e que, portanto, não são causas automáticas do impedimento do Árbitro, que deve levar os fatos à apreciação das Partes ${ }^{33}$. Há, nos casos da Lista Vermelha Renunciável, a necessidade de as Partes reiterarem que desejam a permanência daquele Árbitro no procedimento.

A Lista Laranja, por sua vez, tenta diminuir as divergências a respeito do que se enquadra dentro do discutido conceito de "dúvidas justificáveis". Estão nessa lista as situações mais frequentes e usuais do que deve ser interpretado como fato gerador de dúvida justificável e, em consequência, o

\footnotetext{
${ }^{32}$ Diretrizes da IBA relativas a Conflitos de Interesses em Arbitragem Internacional. Londres: International Bar Association, 2004, parte II, §§1-6.

${ }^{33}$ Diretrizes da IBA relativas a Conflitos de Interesses em Arbitragem Internacional. Londres: International Bar Association, 2004, parte II, §3 e CASEY, J. Brian. Selection of the Tribunal. In: HANESSIAN, Grant e NEWMAN, Lawrence W. (Ed.). International Arbitration Checklists, Second Edition. New York: JurisNet, LLC, 2009, p. 43.
} 
que deve ser revelado pelos Árbitro. Cabe atentar ao fato de que aqui, a revelação não necessariamente vai levar à impugnação automática do Árbitro pelas Partes ${ }^{34}$. Ao contrário, conforme anteriormente falado, por vezes esse tipo de revelação só reitera a confiança das Partes no Árbitro indicado.

A Lista Verde, por fim, revela as situações que não caracterizam conflito de interesses aparente ou efetivos, de forma que não precisam nem mesmo ser revelados pelos Árbitros quando se fizerem presentes ${ }^{35}$.

A fim de melhor ilustrar a aplicação prática da divisão das situações em listas conforme proposta pela IBA, é interessante a análise do fluxograma anexo às Diretrizes da IBA relativas a Conflitos de Interesses em Arbitragem Internacional:

\footnotetext{
${ }^{34}$ Diretrizes da IBA relativas a Conflitos de Interesses em Arbitragem Internacional. Londres: International Bar Association, 2004, parte II, §§4 e 5.

${ }^{35}$ Diretrizes da IBA relativas a Conflitos de Interesses em Arbitragem Internacional. Londres: International Bar Association, 2004, parte II, §6.
} 


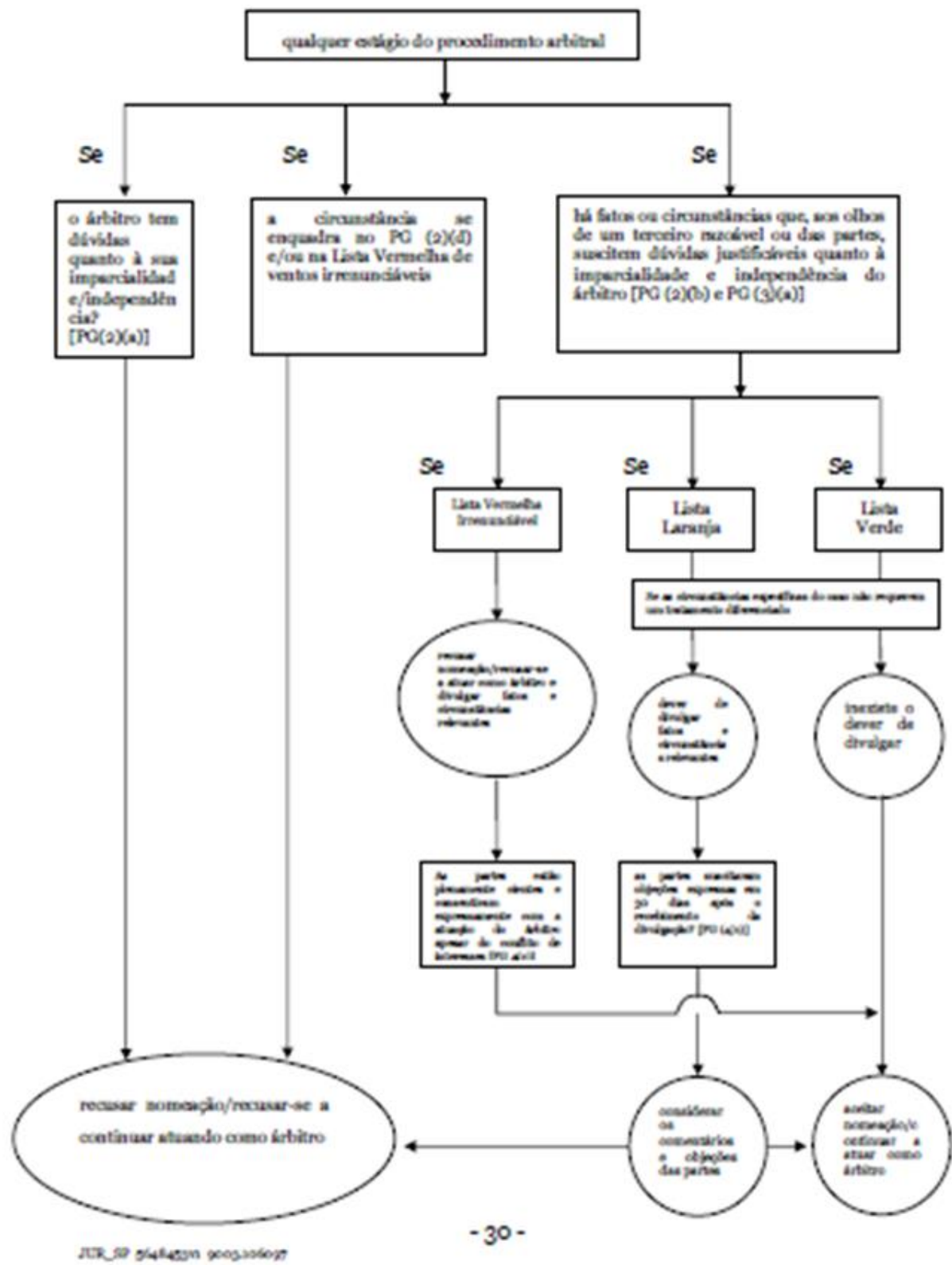

Fonte: Diretrizes da IBA relativas a Conflitos de Interesses em Arbitragem Internacional. Londres: International Bar Association, 2004, p.30.

Em que pese a relevância e a ampla disseminação das IBA Guidelines, é importante destacar que nenhuma das grandes Câmaras Arbitrais adotaramnas ou oficialmente as aplicam ${ }^{36}$. Tal digressão é fundamental para demonstrar que, embora muito úteis em seu papel de orientadoras, as $I B A$

\footnotetext{
${ }^{36}$ CASEY, J. Brian. Selection of the Tribunal. In: HANESSIAN, Grant e NEWMAN, Lawrence W.
} (Ed.). International Arbitration Checklists, Second Edition. New York: JurisNet, LLC, 2009, p.44. 
Guidelines não têm força de lei ou regulamento e, por isso, não podem ser entendidas como vinculantes ${ }^{37}$.

\subsubsection{Notas da CCl}

As Notas às Partes e aos Tribunais Arbitrais sobre a Condução da Arbitragem conforme o Regulamento de Arbitragem da CCI, em sua versão de $1^{\circ}$ de janeiro de 2019 , se propõem a dar uma orientação prática de como o Regulamento da CCI deve ser seguido e interpretado ${ }^{38}$.

Dentre os temas abrangidos pelas Notas está o da "Declaração de Aceitação, Disponibilidade, Imparcialidade e Independência". Nessa sessão, a CCI reitera a obrigação dos Árbitros de agir com independência e imparcialidade e afirma que, para tanto, é necessário que detalhe ao máximo os fatos que possam ser relevantes na hora do preenchimento da Declaração de Aceitação, Disponibilidade, Imparcialidade e Independência ${ }^{39}$.

Além disso, reforça a ideia de que a mera revelação por parte do Árbitro não incorre automaticamente no entendimento das Partes de que há ali qualquer tipo de conflito. Ao contrário, a revelação serve para o Árbitro dizer que, apesar daqueles fatos, ele pessoalmente se entende imparcial e independente ${ }^{40}$.

Após estabelecer um rol exemplificativo de situações que devem ser reveladas ${ }^{41}$, as Notas sinalizam que o Árbitro, na hora de verificar os fatos

\footnotetext{
${ }^{37}$ Diretrizes da IBA relativas a Conflitos de Interesses em Arbitragem Internacional. Londres: International Bar Association, 2004, §6.

${ }^{38}$ Notas às Partes e aos Tribunais Arbitrais sobre a Condução da Arbitragem conforme o Regulamento de Arbitragem da $C C I, 1^{\circ}$ de janeiro de 2019.

${ }^{39}$ Notas às Partes e aos Tribunais Arbitrais sobre a Condução da Arbitragem conforme o Regulamento de Arbitragem da CCI, $1^{\circ}$ de janeiro de 2019, $\S \$ 19-21$.

40 Notas às Partes e aos Tribunais Arbitrais sobre a Condução da Arbitragem conforme o Regulamento de Arbitragem da CCI, $1^{\circ}$ de janeiro de 2019, $\$ 22$.

${ }^{41}$ Notas às Partes e aos Tribunais Arbitrais sobre a Condução da Arbitragem conforme o Regulamento de Arbitragem da CCI, $1^{\circ}$ de janeiro de 2019, §23: "Todo árbitro e todo candidato a árbitro deverá avaliar quais as circunstâncias, eventualmente existentes, que poderiam colocar em
} 
que tem para revelar, deve fazer uma pesquisa não apenas em seus registros pessoais, mas também em seu escritório de advocacia ${ }^{42}$.

Essa sinalização acerca da extensão da revelação à fatos que envolvam o escritório de advocacia é relevante pois, logo em seguida, a CCI afirma que "o árbitro será considerado como tendo a mesma identidade jurídica que seu escritório de advocacia, e toda pessoa jurídica incluirá suas afiliadas" ${ }^{43}$. Esse entendimento, de unificar Árbitro e escritório se mostra extremamente relevante para o cenário jurídico atual, em que muitas vezes os Árbitros são partes de um escritório de grande porte, com filiais em distintos países, e não tinham por costume analisar todas as ligações de seu escritório (por completo) com as Partes e seus Patronos.

Conforme se percebe, as Notas da CCI são relevantes não só para consolidar conceitos gerais como independência, imparcialidade e dever de revela, mas também para trazer inovações decorrentes de divergências e discussões de casos práticos, como é exemplo a equiparação da pessoa do Árbitro com a figura do escritório do qual faz parte.

dúvida sua independência aos olhos das partes ou suscitar dúvidas razoáveis sobre sua imparcialidade. Para tal avaliação, todo árbitro e todo candidato a árbitro deverá levar em conta todas as circunstâncias potencialmente relevantes, inclusive, de maneira não exclusiva, as seguintes: $\square$ o árbitro ou o candidato a árbitro, ou o escritório de advocacia de que faz parte, é ou foi representante legal ou consultor de uma das partes ou de qualquer das suas afiliadas; $\square$ o árbitro ou o candidato a árbitro, ou o escritório de advocacia de que faz parte, atua ou atuou contra uma das partes ou contra qualquer das suas afiliadas; $\square$ o árbitro ou o candidato a árbitro, ou o escritório de advocacia de que faz parte, têm relações de negócios com uma das partes ou com qualquer das suas afiliadas, ou ainda interesse pessoal, de qualquer natureza, no resultado do litígio; $\square$ o árbitro ou o candidato a árbitro, ou o escritório de advocacia de que faz parte, atua ou atuou para uma das partes ou para qualquer das suas afiliadas, na qualidade de diretor, conselheiro, administrador ou de outra forma; $\square$ o árbitro ou o candidato a árbitro, ou o escritório de advocacia de que faz parte, está ou esteve envolvido no litígio, ou expressou opinião sobre o litígio de forma que pudesse afetar sua imparcialidade; $\square$ o árbitro ou o candidato a árbitro têm relação profissional ou pessoal próxima com advogado(a) de uma das partes ou com o respectivo escritório de advocacia; $\square$ o árbitro ou o candidato a árbitro atua ou atuou como árbitro em caso envolvendo uma das partes ou qualquer das suas afiliadas; $\square$ o árbitro ou o candidato a árbitro atua ou atuou como árbitro em procedimento relacionado; $\square$ o árbitro ou o candidato a árbitro já foi anteriormente nomeado como árbitro por uma das partes ou por qualquer das suas afiliadas, ou por advogado de uma das partes ou por seu respectivo escritório de advocacia.

42 Notas às Partes e aos Tribunais Arbitrais sobre a Condução da Arbitragem conforme o Regulamento de Arbitragem da CCI, $1^{\circ}$ de janeiro de 2019, §27.

43 Notas às Partes e aos Tribunais Arbitrais sobre a Condução da Arbitragem conforme o Regulamento de Arbitragem da CCI, $1^{\circ}$ de janeiro de 2019, §28. 


\subsection{Dever de Investigação das Partes}

Complementar ao dever de revelar do Árbitro é o dever de investigação das Partes, ou ainda, dever de curiosidade ${ }^{44}$, que se traduz na obrigação das Partes de, com base naquilo que fora revelado pelos Árbitros, investigar não só novos possíveis conflitos que podem estar relacionados àquele revelado, mas também avaliar a intensidade do fato denunciado pelo Árbitro ${ }^{45}$.

O descumprimento das Partes em relação ao seu dever de investigar pode resultar, inclusive, na perda de seu direito de impugnar os Árbitros pelos sinais de independência e imparcialidade que poderiam ter sido descobertos caso a pesquisa tivesse sido realizada ${ }^{46}$.

Isso porque, nas palavras de António Pinto Leite, entende-se que:

Em todo o caso, sempre que se possa deduzir do comportamento da (contra)parte que agiu de modo a poder permanecer na ignorância e assim poder usar o incidente de suspeição na fase processual que lhe fosse mais conveniente, tal comportamento pode ser qualificado como processualmente abusivo e, por via disso, ser inaceitável ${ }^{47}$.

\footnotetext{
${ }^{44}$ KULL, Nadja Jaisli e ROTH, Andrea. Chapter II: The Arbitrator and the Arbitration Procedure, Challenging Arbitrators for Lack of Independence or Impartiality: Procedural Pitfalls from a Swiss Perspective. In: KLAUSEGGER, Christian, KLEIN, Peter et al. (Eds.). Austrian Yearbook on International Arbitration 2019, p. 232.

${ }^{45}$ BORN, Gary. B. International Commercial Arbitration (Second Edition), 2nd Edition. Kluwer Law International, 2014, p. 1942.

${ }^{46}$ Nesse sentido: "In order to avoid the potential pitfalls of forfeiting the right to challenge an arbitrator and raising the plea of improper constitution in setting aside proceedings against the arbitral award, parties are wise not to rely exclusively on the arbitrator's disclosure but to at least conduct an internet search and consult the arbitrator's website for any obvious connections with the opposing or related parties, e.g. by reviewing press releases. Further, in particular where a party has incomplete knowledge of the grounds for challenge, it should seek clarification directly from the arbitrator" (KULL, Nadja Jaisli e ROTH, Andrea. Chapter II: The Arbitrator and the Arbitration Procedure, Challenging Arbitrators for Lack of Independence or Impartiality: Procedural Pitfalls from a Swiss Perspective. In: KLAUSEGGER, Christian, KLEIN, Peter et al. (Eds.). Austrian Yearbook on International Arbitration 2019, p. 233) Ver também: BORN, Gary. B. International Commercial Arbitration (Second Edition), 2nd Edition. Kluwer Law International, 2014, p. 1943. ${ }^{47}$ LEITE, António Pinto. Independência, Imparcialidade e Suspeição de Árbitro. Revista Brasileira de Arbitragem, 2010, vol. VII, issue 25, p. 118.
} 
A questão do dever de investigação das Partes é suscitada, principalmente, quando, como uma espécie de estratégia procedimental, em um estágio mais avançado do procedimento arbitral, a Parte descobre algum fato ou informação relevante que põe em dúvida a independência ou a imparcialidade do Árbitro, mas que, com a devida atenção ao dever de investigar, poderia ter descoberto antes ${ }^{48}$.

Todavia, insta salientar que não há previsão legal do dever de investigar no ordenamento jurídico brasileiro, motivo pelo qual, talvez, a previsão também não é encontrada em nenhum dos Regulamentos das principais Câmaras do país: CAM-CCBC, CAMARB, CBMA, FGV. Tampouco há previsão em Regulamentos de Câmaras Internacionais ${ }^{49}$.

Acredita-se que a pouca quantidade de material encontrado acerca do tema é reflexo dessa falta de positivação e regulamentação do instituto gerada pelas dificuldades de se delimitar qual seria a extensão do dever de investigar, ou seja, o quanto pode ser esperado de esforço, meios e recursos das Partes ao pesquisarem novos fatos ou se aprofundarem em informações já reveladas pelos Árbitros.

\footnotetext{
48 "If a challenge is based on facts that the challenging party has 'discovered' at some point during the arbitration, the question arises whether that party could not or should not have discovered those facts earlier in time. If the answer to this question is affirmative, the next question is what impact this should have on that party's right to make a challenge later. This issue is a particularly interesting one in respect of the increasing trend of so-called issue conflicts. Can it be expected from the parties and their counsel that, at the outset of the arbitration, they undertake a due diligence and review the academic writings of the arbitrators, their speeches at conferences and the awards rendered by the Tribunals in which they were sitting, failing which a party may be found to have not timely challenged a particular arbitrator on the ground of an issue conflict?" (DAELE, Karel. Challenge and disqualification of arbitrators in international arbitration. The Netherlands: Kluwer Law International, 2012, p.149)

${ }^{49}$ Foram analisados os Regulamentos da CCI, LCIA e Corte Permanente de Arbitragem da Haia.
} 


\section{CAPÍTULO 2 - QUESTÕES RELACIONADAS AO MOMENTO DA IMPUGNAÇÃO}

Antes de adentrar na análise específica da impugnação em cada um dos diferentes estágios da arbitragem acima delimitados, cabe fazer breves anotações sobre o instituto da impugnação de uma forma geral.

Em que pese as peculiaridades de cada Regulamento e legislação que discorra sobre arbitragem criem um procedimento específico para impugnação de Árbitros, esse procedimento sempre se traduz como um incidente processual visto que paralelo à discussão original do litígio ${ }^{50}$.

Sobre a dinâmica do procedimento em si, é elucidativa a passagem de Selma Lemes:

É um procedimento peculiar, pois o árbitro não apresenta uma defesa (no sentido processual do termo), mas presta informações referentes aos fatos suscitados como motivadores de impedimentos. Não se acusa o árbitro, mas se demonstra que para aquele caso ele supostamente não poderia atuar como árbitro e tais argumentos serão avaliados pela instituição de arbitral, pelos demais membros do tribunal arbitral (arbitragem ad hoc) ou pelo judiciário, quando a legislação assim dispor, como será analisado nas seções seguintes deste artigo. ${ }^{51}$

Todo esse procedimento, com espaço para a manifestação do Árbitro em resposta aos argumentos levantados pelas Partes, é necessário e deve ser inteiramente respeitado para que se identifique e afaste impugnações infundadas, com o mero objetivo de atrasar o procedimento ou, ainda, se voltar contra Sentenças desfavoráveis, frustrando, assim, todo o esforço depositado naquele procedimento ${ }^{52}$.

\footnotetext{
${ }^{50}$ LEMES, Selma Maria Ferreira. O Procedimento de Impugnação e Recusa de Árbitro, como sistema de controle quanto à independência e a imparcialidade do julgador. Revista de Arbitragem e Mediação, Jul-Set 2016, vol. 50/2016, versão digital.

${ }^{51}$ LEMES, Selma Maria Ferreira. O Procedimento de Impugnação e Recusa de Árbitro, como sistema de controle quanto à independência e a imparcialidade do julgador. Revista de Arbitragem e Mediação, Jul-Set 2016, vol. 50/2016, versão digital.

52 MENEZES, Caio Campello de. Como Barrar as Táticas de Guerrilha em Arbitragens Internacionais? Revista Brasileira de Arbitragem, 2015m vol. XII, issue 45, p. 85.
} 
Por fim, conforme amplamente defendido neste trabalho, os deveres de independência, imparcialidade e de revelar do Árbitro perduram desde o momento de sua indicação até o fim de sua jurisdição. Da mesma forma, persiste também o direito das Partes de impugnar o Árbitro.

Todavia, importa salientar que o referido direito das Partes vai se modificando a medida em que o procedimento se desdobra ${ }^{53}$. É o que passaremos a analisar.

\subsection{Impugnação no Início do Procedimento Arbitral}

Assim que é nomeado para atuar em um procedimento arbitral, deve o árbitro revelar tudo aquilo que possa comprometer ou ao menos gerar uma dúvida justificada quanto à sua independência e/ou imparcialidade ${ }^{54}$. Cumpre adiantar que é nesse estágio que encontramos o maior número de impugnações que realmente culminam no afastamento dos Árbitros ${ }^{55}$.

Essa realidade se dá porque, nessa fase, o Árbitro, dando início ao seu dever de revelar, apresenta às Partes todos aqueles fatos que entende que possam gerar dúvidas a seu respeito. É, portanto, a primeira vez que as Partes tomam conhecimento de tais fatos e podem, após analisá-los, fazer seu crivo

\footnotetext{
53 "Another recurrent issue is whether the same standards of independence and impartiality apply at all stages of an arbitral proceeding. In particular, are the same standards of impartiality/independence applicable when a court (or arbitral institution) considers whether to: (a) appoint or confirm an arbitrator; (b) remove an arbitrator at the commencement of an arbitration; (c) remove an arbitrator during the course of the arbitral proceedings; and (d) annul or refuse to recognize an arbitral award because of an arbitrator's alleged lack of independence or impartiality?" BORN, Gary. B. International Commercial Arbitration (Second Edition), 2nd Edition. Kluwer Law International, 2014, p. 1820

${ }^{54}$ DOLINGER, Jacob. O Árbitro da Parte - Considerações Éticas e Práticas. Revista Brasileira de Arbitragem, 2005, vol. II, issue 6, p.41.

55 "In practice, challenges to arbitrators are much more likely to succeed if made prior to confirmation of an arbitrator's nomination, or very soon thereafter, rather than during the course of the arbitral proceedings. Various surveys of ICC practice suggest that approximately $70 \%$ of preappointment objections are accepted, while less than $10 \%$ of post-appointment challenges succeed.(1525) The success rate of published ICSID challenges is lower, at approximately $3 \%,(1526)$ while the success rate of challenges in the LCIA is significantly higher, at above $20 \%$." (BORN, Gary. B. International Commercial Arbitration (Second Edition), 2nd Edition. Kluwer Law International, 2014, p. 1919.)
} 
sobre eles. Surgem, aqui, duas alternativas: (i) reiterar a nomeação do Árbitro ou (ii) impugná-1o ${ }^{56}$.

Soma-se a isso o fato de que, nesse primeiro momento, de formação do Tribunal Arbitral, o ônus de se impugnar o Árbitro é menor. Isso porque, não há, ainda, nenhum trabalho, esforço ou tempo a serem perdidos. Todavia, não podemos afirmar que a impugnação do Árbitro nessa fase não incorre em nenhum tipo de prejuízo. Ao contrário, cada Árbitro que é impugnado representa um retardo no início do procedimento, que só começa a fluir depois de composto o Tribunal Arbitral ${ }^{57}$.

Sobre esse momento do procedimento, o Regulamento da CCI estabelece, em seu art. 13.2 que:

O Secretário Geral poderá confirmar, como coárbitros, árbitros únicos e presidentes de tribunais arbitrais, as pessoas designadas pelas partes, ou de acordo com os procedimentos por elas convencionados, desde que a declaração apresentada não contenha nenhuma reserva relativa à imparcialidade ou independência, ou que a declaração de imparcialidade ou independência com reservas não tenha gerado objeções das partes. Tal confirmação deverá ser informada à Corte na sessão seguinte. Se o Secretário Geral considerar que um coárbitro, árbitro único ou presidente do tribunal arbitral não deve ser confirmado, a questão será submetida à decisão da Corte.

Percebe-se que, caso as Partes desaprovem as revelações realizadas pelos Árbitros em sua Declaração de Aceitação, Disponibilidade, Imparcialidade e Independência, o procedimento nem mesmo se inicia com aquela composição do Tribunal Arbitral ${ }^{58}$.

\footnotetext{
${ }^{56}$ BENEDETTELLI, Massimo V., CONSOLO, Claudio e RADICATI DI BROZOLO, Luca. Commentario breve al diritto dell' arbitrato nazionale ed internazionale. Milão: Casa Editrice Dott. Antonio Milani, 2010, pp. 163 e 164

${ }^{57}$ BORN, Gary. B. International Commercial Arbitration (Second Edition), 2nd Edition. Kluwer Law International, 2014, p. 1820

58 "The extensive disclosure requirements under Article 11(2) are one of the primary reasons for the relatively low number of chalenges against ICC arbitrators, and their even lower success rate. These requirements allow the parties to express their concerns about arbitrators from the outset of the arbitration by objecting to confirmations, thereby avoiding the potentially high costs and significant delays associated with challenges. The more detailed nature of the disclosure requirements in the 2012 Rules should flush out even more challenges early." (FRY, Jason; GREENBERG, Simon e MAZZA, Francesca. The Secretariat's Guide to ICC Arbitration: A Practical Commentary on the
} 
Disposição semelhante é a que consta dos arts. 4.6, 4.7 e 4.8 do Regulamento do CAM-CCBC, que se segue:

4.6. A Secretaria do CAM-CCBC informará às Partes e aos árbitros sobre as indicações realizadas. Nesta oportunidade, os árbitros indicados serão solicitados a preencher Questionário de Conflitos de Interesse e Disponibilidade do CAMCCBC, abreviadamente denominado Questionário, no prazo de 10 (dez) dias.

4.6.1. O Questionário será elaborado pela Diretoria do CAM-CCBC em conjunto com o Conselho Consultivo, objetivando colher informações sobre a imparcialidade e independência dos árbitros, bem como sua disponibilidade de tempo e demais informações relativas ao seu dever de revelação.

4.7. As respostas aos Questionários e eventuais fatos relevantes serão encaminhados às Partes, oportunidade em que lhes será conferido prazo de 10 (dez) dias para manifestação.

4.8. Em caso de manifestação pelas partes de objeção relacionada à independência, imparcialidade ou qualquer matéria relevante referente ao árbitro, será concedido prazo de 10 (dez) dias para manifestação do árbitro envolvido, após o que as partes terão 10 (dez) dias para apresentação de eventual impugnação que será processada nos termos do artigo 5.4.

Conforme se percebe, no CAM-CCBC as Partes também têm a oportunidade de analisar e se manifestar previamente acerca de suas impressões sobre tudo aquilo que fora revelado pelo Árbitro por meio de seu Questionário de Conflitos de Interesse e Disponibilidade. Podem, ainda, pedir esclarecimentos e complementações daquilo que fora revelado ${ }^{59}$.

Para o preenchimento do Questionário de Conflitos de Interesse e Disponibilidade, o CAM-CCBC recomenda a leitura de seu Código de Ética,

2012 ICC Rules of Arbitration from the Secretariat of the ICC International Court of Arbitration. Paris: International Chamber of Commerce (ICC), 2012, p. 174)

${ }^{59}$ WALD, Arnoldo; BORJA, Ana Gerdau; LONGO, Bryan; TERASHIMA, Eduardo Ono; VIEIRA, Maíra de Melo; CASADO FILHO, Napoleão e GAGLIARDI, Rafael Villar. Article 4 Commencement of the Arbitration. In: STRAUBE, Frederico José, FINKELSTEIN, Cláudio e CASADO FILHO, Napoleão (Eds.). The CAM-CCBC Arbitration Rules 2012: A Commentary. The Hague: Eleven International Publishing, 2016, p.88. 
que indica o que deve ser revelado, seus motivos, e qual a conduta esperada do Árbitro durante o procedimento ${ }^{60}$.

O mesmo dispositivo se repete, ainda, no Regulamento da CAMARB:

4.4 Salvo convenção em contrário, caso as partes optem pela constituição de Tribunal Arbitral com 3 (três) membros, caberá a cada uma delas a nomeação de um árbitro no prazo fixado no item 4.2. Após a manifestação de disponibilidade, não impedimento, independência e imparcialidade dos árbitros indicados, não havendo impugnação, estes serão intimados para, no prazo de 10 (dez) dias, indicarem conjuntamente o terceiro árbitro, que funcionará como presidente do Tribunal Arbitral. Não sendo alcançado o consenso entre os árbitros indicados pelas partes, a indicação do árbitro presidente caberá à Diretoria da CAMARB.

\subsection{Impugnação no Curso do Procedimento Arbitral}

Nos casos de Impugnação ocorridos após a constituição do Tribunal Arbitral e antes da prolação da Sentença Arbitral Final, os prejuízos, tanto de tempo quanto de esforço, para a impugnação do Árbitro já são significativamente maiores pois, na maioria dos casos, requer a repetição - o reinício - de todo o procedimento arbitral, e não apenas o afastamento do Árbitro impugnado ${ }^{61}$.

Há de se atentar, ainda, para a necessidade de impedir a ocorrência de casos em que, na realidade, o objetivo das Partes para a impugnação é, de fato, gerar esse atraso no procedimento ${ }^{62}$.

${ }^{60}$ WALD, Arnoldo; BORJA, Ana Gerdau; LONGO, Bryan; TERASHIMA, Eduardo Ono; VIEIRA, Maíra de Melo; CASADO FILHO, Napoleão e GAGLIARDI, Rafael Villar. Article 4 Commencement of the Arbitration. In: STRAUBE, Frederico José, FINKELSTEIN, Cláudio e CASADO FILHO, Napoleão (Eds.). The CAM-CCBC Arbitration Rules 2012: A Commentary. The Hague: Eleven International Publishing, 2016, p. 86.

${ }^{61}$ BORN, Gary. B. International Commercial Arbitration (Second Edition), 2nd Edition. Kluwer Law International, 2014, p. 1820.

62 "The procedure for challenging arbitrators can undoubtedly be misused by parties in an attempt to create delays or antagonize the challenged arbitrator." (FRY, Jason; GREENBERG, Simon e MAZZA, Francesca. The Secretariat's Guide to ICC Arbitration: A Practical Commentary on the 2012 ICC Rules of Arbitration from the Secretariat of the ICC International Court of Arbitration. Paris: International Chamber of Commerce (ICC), 2012, p. 175) 
Nesse estágio, não cabem mais impugnações ao Árbitro baseadas em motivos que já haviam sido revelados por ele quando do início do procedimento $^{63}$. Entende-se, dessa afirmação, que só poderão ser suscitadas como causas de impugnação, durante essa fase do procedimento arbitral, fatos novos ou informações que não foram reveladas pelos Árbitros e que só foram descobertas no curso da Arbitragem.

Uma vez que o procedimento arbitral já fora iniciado, as Câmaras costumam apresentar regras diferentes daquelas dispostas para o momento de indicação do Árbitro.

No Regulamento da CCI, por exemplo, o art. 14 determina que:

1 A impugnação de um árbitro por alegada falta de imparcialidade ou independência ou por quaisquer outros motivos deverá ser feita por meio da apresentação de uma declaração por escrito à Secretaria, especificando os fatos e circunstâncias que lhe servem de fundamento.

2 A impugnação deve, sob pena de rejeição, ser apresentada por uma das partes dentro do prazo de trinta dias seguintes ao recebimento, pelo impugnante, da notificação de nomeação ou confirmação do árbitro, ou dentro de trinta dias a partir da data em que o impugnante tomou conhecimento dos fatos e circunstâncias em que se fundamenta a impugnação, no caso de esta data ser subsequente ao recebimento da referida notificação.

3 Compete à Corte pronunciar-se sobre a admissibilidade e, se necessário, sobre os fundamentos da impugnação, após a Secretaria ter dado a oportunidade, ao árbitro impugnado, à outra ou às outras partes e a quaisquer outros membros do tribunal arbitral de se manifestarem, por escrito, em prazo adequado. Estas manifestações devem ser comunicadas às Partes e aos Árbitros.

\footnotetext{
63 "In order to avoid any risk of being declared in violation of the obligation of impartiality and independence, a prospective arbitrator should disclose all facts that could reasonably be considered to be grounds for disqualification. If he or she does so (and no objection is made), any subsequent challenge during or after the proceedings should be unsuccessful. The right to an independent and impartial arbitrator is deemed to have been waived in respect of objections founded upon facts contained in the disclosure statement." (REDFERN, Alan; HUNTER, Martin; BLACKABY, Nigel e PARTASIDES, Constantine. Law and Practice of International Comrnercial Arbitration. Oxford: Oxford University Press, 2009, p. 268.)
} 
Ao estabelecer o escopo do artigo ora analisado, a CCI é clara ao dizer que o procedimento de impugnação nele previsto só é válido para casos em que o Árbitro já tiver sido apontado ou confirmado pela Corte da $\mathrm{CCI}^{64}$.

Além disso, a Câmara defende que a obrigatoriedade de a impugnação ser feita através de documento escrito é uma importante barreira para se evitar impugnações fundamentadas em motivos frívolos ${ }^{65}$.

Tal impugnação deve, ainda, ser apresentada em um prazo máximo de 30 (trinta) dias contados do conhecimento pela Parte do fato que a levou a impugnar o Árbitro ${ }^{66}$. Esse prazo limite é importante para evitar que a Parte escolha um "momento ideal" para poder fazer a impugnação do Árbitro ${ }^{67}$.

Os arts. 5.3 e 5.4 do Regulamento do CAM-CCBC, por sua vez:

5.3. Compete ao árbitro declarar, a qualquer momento, seu eventual impedimento e recusar sua nomeação, ou apresentar renúncia.

5.4. As partes poderão impugnar os árbitros por falta de independência, imparcialidade, ou por motivo justificado no prazo de 15 (quinze) dias do conhecimento do fato, sendo a impugnação julgada por Comitê Especial constituído por 3 (três) membros do Corpo de Árbitros nomeados pelo Presidente do CAM-CCBC.

\footnotetext{
${ }^{64}$ FRY, Jason; GREENBERG, Simon e MAZZA, Francesca. The Secretariat's Guide to ICC Arbitration: A Practical Commentary on the 2012 ICC Rules of Arbitration from the Secretariat of the ICC International Court of Arbitration. Paris: International Chamber of Commerce (ICC), 2012, pp. 170 e 171.

${ }^{65}$ FRY, Jason; GREENBERG, Simon e MAZZA, Francesca. The Secretariat's Guide to ICC Arbitration: A Practical Commentary on the 2012 ICC Rules of Arbitration from the Secretariat of the ICC International Court of Arbitration. Paris: International Chamber of Commerce (ICC), 2012, p. 171.

${ }^{66}$ FRY, Jason; GREENBERG, Simon e MAZZA, Francesca. The Secretariat's Guide to ICC Arbitration: A Practical Commentary on the 2012 ICC Rules of Arbitration from the Secretariat of the ICC International Court of Arbitration. Paris: International Chamber of Commerce (ICC), 2012, p. 177.

${ }^{67}$ FRY, Jason; GREENBERG, Simon e MAZZA, Francesca. The Secretariat's Guide to ICC Arbitration: A Practical Commentary on the 2012 ICC Rules of Arbitration from the Secretariat of the ICC International Court of Arbitration. Paris: International Chamber of Commerce (ICC), 2012, p. 176.
} 
Os referidos artigos, como podemos perceber, corroboram o entendimento de que o Árbitro deve continuar independente, imparcial e desimpedido durante todo o curso do procedimento ${ }^{68}$.

A CAMARB, novamente seguindo a linha do CCBC, dispõe que:

4.11 Deverá o árbitro informar imediatamente qualquer fato superveniente que, no curso do procedimento, possa ocasionar dúvida justificável quanto à sua imparcialidade, independência, competência técnica ou disponibilidade ou que possa, de alguma forma, causar impedimento ou suspeição para o julgamento da controvérsia.

5.1 No prazo de 10 (dez) dias do recebimento da declaração de disponibilidade, independência e imparcialidade ou da informação de que trata o item 4.11 , qualquer das partes poderá impugnar o árbitro que não atenda aos requisitos da convenção de arbitragem ou de legislação eventualmente aplicável, incorra em qualquer das hipóteses de impedimento ou suspeição previstas na lei de arbitragem, ou não possua a disponibilidade para atuar no procedimento arbitral.

5.2 Em caso de impugnação, será o árbitro intimado pela Secretaria da CAMARB para que se manifeste no prazo de 5 (cinco) dias, do que será concedida vista às partes por igual prazo.

5.3 A impugnação será decidida por Comitê especialmente composto para esse fim por 3 (três) integrantes da Lista de Árbitros da CAMARB, nomeados pelo Presidente da CAMARB em conjunto com outro Diretor.

(...)

5.5 O Comitê deverá proferir decisão no prazo de 30 (trinta) dias contados da última aceitação dos membros indicados, podendo tal prazo ser prorrogado por ato do Presidente da CAMARB.

A CAMARB, bem como o CCBC, prevê a composição de um Comitê de Árbitros criado especificamente para analisar e decidir acerca do pedido de impugnação.

${ }^{68}$ FORBES, Carlos Suplicy e KOBAYASHI, Patrícia S. Article 5 - Arbitral Tribunal. In: STRAUBE, Frederico José, FINKELSTEIN, Cláudio e CASADO FILHO, Napoleão (Eds.). The CAM-CCBC Arbitration Rules 2012: A Commentary. The Hague: Eleven International Publishing, 2016, p. 120 
Por fim, o art. 12 da UNCITRAL é expresso ao dizer que a parte só pode impugnar o Árbitro que indicou nos casos em que o motivo da impugnação tenha sido conhecido posteriormente a sua nomeação:

1. Any arbitrator may be challenged if circumstances exist that give rise to justifiable doubts as to the arbitrator's impartiality or independence.

2. A party may challenge the arbitrator appointed by it only for reasons of which it becomes aware after the appointment has been made.

\subsection{Impugnação Depois da Sentença Arbitral Final}

Nessa fase mais avançada do procedimento arbitral, há de se ter um maior cuidado em relação à Impugnação do Árbitro. Isso porque, após a prolação da Sentença Arbitral Final, é incontestável que, caso a impugnação seja aceita, haverá prejuízos em termos de tempo e dinheiro ${ }^{69}$.

É, portanto, por este motivo que a doutrina afirma que, após a prolação da Sentença, não basta apenas a alegação do dever de violação ou mesmo a apresentação de indícios que, em abstrato, prejudicariam a independência ou a imparcialidade do Árbitro. Há a necessidade de se comprovar que, no caso concreto, o Árbitro agiu de forma parcial no curso do procedimento ${ }^{70}$.

Essa maior rigidez na análise da impugnação após a Sentença decorre do fato de que, muitas vezes, essa impugnação é apenas um reflexo de

\footnotetext{
${ }^{69}$ Accordingly, cases where a party's later challenge to an arbitrator are admissible must be limited to entirely exceptional situations supported by evidence that there is objectively no way suck circumstances could have been determined by a party exercising its rights with sufficient caution. It should be noted that international practice is highly sensitive to late challenges to an arbitrator and limits the admissibility of such challenges to isolated genuinely eligible cases (BELOHLÁVEK, Alexander J. Arbitration Law of Czech Republic: Practice and Procedure. New York: JurisNet, LLC, 2013, p. 599).

${ }^{70}$ WALD, Arnoldo. A Ética e a Imparcialidade na Arbitragem. Revista de Arbitragem e Mediação, Out-Dez 2013, vol. 39/2013, versão digital.
} 
insatisfação da Parte com o resultado da Sentença proferida, e não um real argumento de falta de independência ou imparcialidade do Árbitro ${ }^{71}$.

A análise dos Regulamentos realizada no capítulo anterior é reiterada nesse, visto que todos eles só estabelecem distinções - quando o fazem - para as impugnações realizadas antes/depois da confirmação da nomeação do Árbitro. A fim de se evitar repetição desnecessárias, nos absteremos de apresentá-los novamente.

71 MENEZES, Caio Campello de. Como Barrar as Táticas de Guerrilha em Arbitragens Internacionais? Revista Brasileira de Arbitragem, 2015, vol. XII, issue 45, p. 85. 


\section{CAPÍTULO 3 - ANÁLISE DE CASOS}

\subsection{Caso no 1 de Impugnação no Início do Procedimento}

\subsubsection{Fundamentos da Impugnação}

No caso LCIA $n^{\circ} 142862$, cujo resumo foi recentemente publicado na base de dados online da própria LCIA ${ }^{72}$, foi composto um Tribunal Arbitral com três Árbitros para a solução de uma controvérsia que envolvia um Estado.

Todavia, dois dias após a indicação, que já foi realizada com o envio do Curriculum Vitae e do Statement of Independence and Availability and Consent to Appointment, o Requerente, em vista do art. 10.3 do Regulamento da LCIA $^{73}$, impugnou a nomeação de um dos Árbitros.

Como fundamento da impugnação, a Parte indicou que o Árbitro era nacional do Estado Parte e, ainda, professor de uma universidade do Estado Parte, o que atentaria contra sua independência e imparcialidade.

Para além desses fatos, foi identificado que o Presidente da empresa Requerida (cujo Estado era sócio controlador), fazia parte do Conselho de Administradores da Universidade.

\footnotetext{
${ }^{72}$ Os resumos dos casos de impugnação da LCIA podem ser encontrados através do seguinte link: <https://www.lcia.org/challenge-decision-database.aspx>. Acessado em: 15 de junho de 2019.

73 Íntegra do art. 10.3 do Regulamento da LCIA: "10.3 A party challenging an arbitrator under Article 10.1 shall, within 14 days of the formation of the Arbitral Tribunal or (if later) within 14 days of becoming aware of any grounds described in Article 10.1 or 10.2, deliver a written statement of the reasons for its challenge to the LCIA Court, the Arbitral Tribunal and all other parties. A party may challenge an arbitrator whom it has nominated, or in whose appointment it has participated, only for reasons of which it becomes aware after the appointment has been made by the LCIA Court."
} 


\subsubsection{Defesa}

O Estado, em sua posição de Parte, afirmou que a Universidade e o Estado são entes públicos autônomos, com personalidades jurídicas diferentes, e que a Universidade não faz parte do governo, de forma que o Árbitro impugnado não pode ser entendido como um oficial do Estado.

Alegou, ainda, que é usual a atuação de professores universitários na qualidade de Árbitros em Arbitragens comerciais e de investimentos que envolvam o Estado.

O Árbitro impugnado, por sua vez, listou três casos em que a Corte da CCI decidiu que o emprego indireto de um Árbitro por um Estado que é Parte da arbitragem não o desqualifica para atuar como tal. Todavia, reiterou o entendimento de que ser empregado da Universidade não o torna um agente estatal.

Sobre a questão do Conselho de Administradores da Universidade, afirmou que ele não tem funções de administração ou supervisão, mas que apenas atua como um corpo responsável por atrair financiamentos não governamentais para projeto científicos desenvolvidos na Universidade.

Uma vez que o Conselho é composto por diversos Presidentes de outras companhias e até mesmo bancos, seria compreensível a presença do Presidente da empresa Requerida como membro do Conselho e, assim, nenhuma pessoa razoável suscitaria dúvidas a respeito do Árbitro professor da Universidade. 


\title{
3.1.3. Decisão sobre a Impugnação
}

\author{
A decisão da LCIA sobre a impugnação ora estudada foi realizada com \\ fundamento nos arts. $10.1^{74}, 5.3^{75}, 5.4^{76}$ e $5.5^{77}$ do Regulamento da LCIA.
}

\author{
Inicialmente, o Vice-Presidente da LCIA $^{78}$ afirmou que o conceito \\ "dúvidas justificáveis" presente no art. 5.4 do Regulamento trata de uma \\ análise objetiva da percepção subjetiva a respeito do Árbitro impugnado.
} Nesse sentido, afirmou que:

\footnotetext{
${ }^{74}$ Íntegra do art. 10.1 do Regulamento da LCIA: “10.1 The LCIA Court may revoke any arbitrator's appointment upon its own initiative, at the written request of all other members of the Arbitral Tribunal or upon a written challenge by any party if: (i) that arbitrator gives written notice to the LCIA Court of his or her intent to resign as arbitrator, to be copied to all parties and all other members of the Arbitral Tribunal (if any); (ii) that arbitrator falls seriously ill, refuses or becomes unable or unfit to act; or (iii) circumstances exist that give rise to justifiable doubts as to that arbitrator's impartiality or independence."

75 Íntegra do art. 5.3 do Regulamento da LCIA: "5.3 All arbitrators shall be and remain at all times impartial and independent of the parties; and none shall act in the arbitration as advocate for or representative of any party. No arbitrator shall advise any party on the parties' dispute or the outcome of the arbitration."

76 Íntegra do art. 5.4 do Regulamento da LCIA: "5.4 Before appointment by the LCIA Court, each arbitral candidate shall furnish to the Registrar (upon the latter's request) a brief written summary of his or her qualifications and professional positions (past and present); the candidate shall also agree in writing fee-rates conforming to the Schedule of Costs; the candidate shall sign a written declaration stating: (i) whether there are any circumstances currently known to the candidate which are likely to give rise in the mind of any party to any justifiable doubts as to his or her impartiality or independence and, if so, specifying in full such circumstances in the declaration; and (ii) whether the candidate is ready, willing and able to devote sufficient time, diligence and industry to ensure the expeditious and efficient conduct of the arbitration. The candidate shall furnish promptly such agreement and declaration to the Registrar."

77 Íntegra do art. 5.5 do Regulamento da LCIA: "5.5 If appointed, each arbitral candidate shall thereby assume a continuing duty as an arbitrator, until the arbitration is finally concluded, forthwith to disclose in writing any circumstances becoming known to that arbitrator after the date of his or her written declaration (under Article 5.4) which are likely to give rise in the mind of any party to any justifiable doubts as to his or her impartiality or independence, to be delivered to the LCIA Court, any other members of the Arbitral Tribunal and all parties in the arbitration."

${ }^{78}$ A aplicação conjunta dos arts. 10.6 do Regulamento da LCIA com o parágrafo D.3(b) da Constituição da LCIA fazem com que a competência para analisar e julgar casos de impugnação de Árbitros seja do Vice-Presidente da LCIA. Confira-se a íntegra do art. 10.6 do Regulamento: "10.6 Unless the parties so agree or the challenged arbitrator resigns in writing within 14 days of receipt of the written statement, the LCIA Court shall decide the challenge and, if upheld, shall revoke that arbitrator's appointment. The LCIA Court's decision shall be made in writing, with reasons; and a copy shall be transmitted by the Registrar to the parties, the challenged arbitrator and other members of the Arbitral Tribunal (if any). A challenged arbitrator who resigns in writing prior to the LCIA Court's decision shall not be considered as having admitted any part of the written statement." e a íntegra parágrafo D.3(b) da Constituição: "D. Functions of the Court (...) 3. All other functions of the Court under Articles D.1(a) and D.1(b) shall be performed in the name of the Court: (...)(b)by an Honorary Vice President, or a former Vice President of the Court, appointed by the President or a Vice President;"
} 
The objective evaluation of the justifiable doubt criterion focuses on the justifiable aspect of these doubts. These subjective doubts go beyond a third party's personal feelings, they must be objectively justifiable. It is not only someone's perception; it is whether the facts bear out that person's subjective appraisal of the situation. Said otherwise, in order for the challenge to succeed, a reasonable third party reviewing the case at hand should not have doubts supported by the circumstances of the case as to the independence of the arbitrator or as to his or her impartiality. ${ }^{79}$

Atestou, ainda, que o padrão de independência e imparcialidade para fins de impugnação de Árbitros adotado pela LCIA está em consonância com aquele previsto pelo art. 12 da Lei Modelo da UNCITRAL ${ }^{80}$, com o disposto na Lei Inglesa sobre arbitragem ${ }^{81}$ e com as IBA Guidelines.

A questão que o Vice-Presidente da LCIA se propôs a responder foi se, no caso concreto, os fatos fundamentadores da impugnação (i) poderiam criar dúvidas justificadas sobre a independência e a imparcialidade e (ii) seriam capazes de prejudicar a condução do procedimento.

Adentrando no mérito da impugnação, entendeu que o simples fato de ser nacional do Estado Parte, bem como professor de uma Universidade do mesmo, não era suficiente para a impugnação do Árbitro.

Todavia, a questão da presença do Presidente da empresa Requerida no Conselho de Administração da Universidade, ainda que apenas para tratativas externas de investimentos em pesquisas acadêmicas e científicas, foi entendida como atentatória ao dever de independência e imparcialidade do Árbitro que era professor da Universidade Estatal.

79 LCIA Reference 142862, de 2 de junho de 2015, §45. Disponível em: <https://www.lcia.org/challenge-decision-database.aspx>. Acessado em: 15 de junho de 2019.

${ }^{80}$ Íntegra do art. 12 da Lei Modelo da UNCITRAL: "Artigo 12. ${ }^{\circ}$ Fundamentos de objeção. (1) Quando uma pessoa for indicada com vistas à sua eventual nomeação como árbitro, fará notar todas as circunstâncias que possam suscitar dúvidas fundamentadas sobre sua imparcialidade ou independência. A partir da data da sua nomeação e durante todo o procedimento arbitral, o árbitro fará notar sem demora às partes as referidas circunstâncias, a menos que já o tenha feito. (2) Um árbitro só pode ser objetado se existirem circunstâncias que possam suscitar dúvidas fundamentadas sobre sua imparcialidade ou independência ou se não possuir as qualificações que as partes acordaram. Uma parte só pode objetar um árbitro nomeado por si, ou em cuja nomeação tiver participado, por um motivo de que tenha tido conhecimento apenas após essa nomeação."

${ }^{81}$ As partes haviam indicado que a lei aplicável ao procedimento era a inglesa. 
Diante de todos esses argumentos, o Vice-Presidente da LCIA admitiu e concordou com a impugnação, substituindo o Árbitro.

\subsection{Caso no 2 de Impugnação no Início do Procedimento}

\subsubsection{Fundamentos da Impugnação}

O segundo caso a ser apresentado de impugnação no Início do Procedimento também é da base de dados da LCIA ${ }^{82}$. No procedimento $\mathrm{n}^{\mathrm{o}}$ 173566, a LCIA indicou três Árbitros para a composição de um Tribunal Arbitral.

Ocorre que, logo após sua indicação, um dos Coárbitros revelou que, enquanto estava no Bar, havia atuado em nome e também contra a Requerente. Além disso, durante o Bar, teria sido instruído pelo Advogado da Requerente. Sobre essas três situações, informou que não se lembrava sobre quantas vezes ou sob quais circunstâncias elas teriam ocorrido.

Por fim, informou que conhecia uma pessoa que era funcionária da Requerente há quarenta anos, mas que eram apenas conhecidos da faculdade, e não amigos próximos.

As Requerentes, tendo entendido a revelação do Coárbitro como muito vaga, pediu a ele que detalhasse os fatos e circunstâncias de sua relação com a Requerente e seus Patronos.

Em atenção a esse pedido, o Coárbitro deu a seguinte resposta:

"I practised at the Bar between 1975 and 2000. My practice ceased [...] on my appointment to [Court A]. Whilst not wishing to engage in semantics, this I would respectfully suggest is a little more than "several" years ago. During that time I was

${ }^{82}$ Os resumos dos casos de impugnação da LCIA podem ser encontrados através do seguinte link: $<$ https://www.lcia.org/challenge-decision-database.aspx >. Acessado em: 15 de junho de 2019. 
instructed by most, if not perhaps all, of the firms solicitors then practising in London in the [relevant] field. During my [...] years sitting in [Court A] and [...] years sitting in [Court B] I also of course dealt judicially with many cases involving those same solicitors and their clients. I am advised by my clerk [...] that such records as survive in chambers of my practice are of fee notes rendered. [My clerk] has searched the system. A search for [the Claimant's name] reveals no cases. Of course a fee note rendered to a solicitor citing [a different means of referring to the matter than the Claimant's name] may have related to [the Claimant]. The name of [an individual] at [the Claimant company] is on the chambers' system, but there is no record of my having been instructed by him or having worked with him. That accords with my own, imperfect, recollection. I still think it likely that I must have acted for (and against) [the Claimant] but I have no further recollection. The records show one case for [the Claimant's counsel]. Apparently I gave advice in June 1994 [...]. I do not know whether this was the only time I acted for [the Claimant's counsel]. I mean them no disrespect when I record, as is I have no doubt the case, that I may have difficulty now in distinguishing them in my recollection from one or two other small niche [...] firms [in the relevant area] which were started up at much the same time by solicitors whom I knew from longer established firms.

I am sorry that I cannot be more helpful.." ${ }^{83}$

Novamente em dúvidas sobre o revelado pelo Coárbitro, a Requerida pediu novos esclarecimentos sobre a relação existente entre o Coárbitro, a Requerente e seus advogados.

Após o recebimento das respostas, a Parte impugnou o Árbitro.

\subsubsection{Defesa}

A Requerente informou que só havia tido contato com o Coárbitro uma vez em 2014, quando ele proferiu uma decisão contra a Requerente. A respeito da ligação com os Advogados, afirmou que nunca houve nenhum contato entre eles.

O Coárbitro, por sua vez, informou que já havia devidamente cumprido com seu dever de revelação ao assinar o Termo de Independência

83 LCIA Reference 173566, de 21 de julho de 2017, §1.5. Disponível em: <https://www.lcia.org/challenge-decision-database.aspx>. Acessado em: 15 de junho de 2019. 
e ao prestar informações adicionais às Partes, de forma que não haveria mais o que acrescentar.

\subsubsection{Decisão sobre a Impugnação}

A LCIA entendeu que a impugnação fora feita dentro do prazo previsto no art. 10.1 de seu Regulamento e, por isso, passou à análise do mérito.

O Vice-Presidente disse não concordar com a Requerida sobre o entendimento de que as respostas dadas pelo Coárbitro teriam sido vagas e inconsistentes. Uma vez que os principais fatos teriam ocorrido no ano 2000, já não seria mais necessária a sua revelação uma vez que, a princípio, não colocariam em risco sua independência ou imparcialidade.

Ao fim de sua análise, o Vice-Presidente rejeitou a impugnação ao Coárbitro.

\subsection{Caso no 1 de Impugnação no Curso do Procedimento}

\subsubsection{Fundamentos da Impugnação}

O Coárbitro impugnado, quando do envio da sua Declaração de Aceitação, Disponibilidade, Imparcialidade e Independência, informou às Partes que já havia sido indicado pelo Requerido em um Procedimento Arbitral encerrado em 2016, ou seja, um ano antes do início do Procedimento ora estudado. Informou também que ainda estava atuando em outros dois Procedimentos que envolviam o escritório do Requerido.

Diante de tais revelações, o Requerente impugnou o Coárbitro, o que foi inadmitido pela Corte da CCI. 
O Procedimento Arbitral teve continuidade por um ano até que foi publicada, pela revista Global Arbitration Review (GAR), uma notícia informando que o Coárbitro havia, no outro procedimento em que havia sido indicado pelo Requerido, falhado em seu dever de revelação.

O referido fato gerou no Requerente dúvidas acerca da independência e imparcialidade do Coárbitro. A fim de saná-las, foram requisitadas informações adicionais sobre a relação existente entre o Coárbitro e o Requerido.

Em resposta, o Coárbitro revelou três casos adicionais em que atuava, diferentes dos anteriormente revelados, e que o escritório Patrono do Requerido, ainda que não diretamente, estava envolvido. Após tais revelações, o Requerente novamente impugnou o Coárbitro.

A Parte, ao proceder sua impugnação, além de destrinchar os fatos até aqui narrados, alegou que o simples fato de o Coárbitro apenas ter revelado três dos seis casos em que tinha algum tipo de ligação com o Requerido ou seu Patrono, já era suficiente para criar uma falta de confiança na Independência e Imparcialidade do Coárbitro.

\subsubsection{Defesa}

Em sua defesa, o Coárbitro impugnado informou que não vislumbrava nada que pudesse, no caso concreto, afetar sua independência ou imparcialidade.

Inicialmente, informou que é sempre classificado como um dos principais e mais procurados Árbitros de seu país, de forma que sempre está envolvido em grandes litígios dos maiores e mais renomados escritórios locais. Alegou, ainda, que o mercado sobre o qual o Procedimento Arbitral 
versava é muito restrito tanto em termos de clientes quanto em termos de escritórios de advocacia especializados.

Defendeu, ainda, que o mero contato ou conhecimento com a Parte que o indicou ou seus Patronos não era suficiente para estabelecer entre eles uma relação suficientemente forte que afetasse sua independência e imparcialidade.

Sobre o processo interno de escolha daquilo que revelaria ou não, entendeu que apenas três dos seis casos que foram apontados como determinantes para sua Impugnação de fato teriam um potencial de gerar dúvidas justificáveis nas Partes dentro do padrão internacional. Todos as outras três situações estariam, a seu ver, englobadas na Lista Verde das $I B A$ Guidelines.

\subsubsection{Decisão sobre a Impugnação}

A Corte da CCI, em sua decisão, analisou, no primeiro momento, a admissibilidade da Impugnação. Nesse sentido, a Corte considerou que três dos seis casos que levaram à impugnação já haviam sido revelados pelo Coábitro quando em sua Declaração de Aceitação, Disponibilidade, Imparcialidade e Independência.

Todavia, em relação às informações adicionais recebidas acerca dos outros três casos, a Impugnação ainda era tempestiva de acordo com o Art. 14(2) do Regulamento da $\mathrm{CCI}^{84}$.

\footnotetext{
${ }^{84}$ Íntegra do art. 14(2) do Regulamento da CCI: “A impugnação deve, sob pena de rejeição, ser apresentada por uma das partes dentro do prazo de trinta dias seguintes ao recebimento, pelo impugnante, da notificação de nomeação ou confirmação do árbitro, ou dentro de trinta dias a partir da data em que o impugnante tomou conhecimento dos fatos e circunstâncias em que se fundamenta a impugnação, no caso de esta data ser subsequente ao recebimento da referida notificação".
} 
Passando para a análise do Mérito, a Corte atentou aos arts. 11(1) ${ }^{85} \mathrm{e}$ $14(1)^{86}$ do Regulamento. Relembrou que a atuação do Coárbitro nos três primeiros casos revelados já havia sido discutida pela Corte anteriormente, que declarou que o contato entre ele e a Parte não configuraria qualquer tipo de dano à sua independência e imparcialidade.

A respeito dos três outros casos, informou que tanto a lista das ICC Notes quanto as IBA Guidelines não são exaustivas em relação a tudo aquilo que deve ser revelado e que, portanto, não caberia ao Coárbitro deixar de revelar algo relevante acerca de sua independência e imparcialidade.

Por outro lado, a Corte afirma que o fato de o Coárbitro não ter revelado situações em que entendeu que as Partes não poderiam suscitar dúvidas quanto à sua independência e imparcialidade não é automaticamente um indício de violação de qualquer desses deveres.

A situação do Coárbitro foi agravada pelo fato de que, quando solicitadas as informações adicionais, ele respondeu de forma grosseira, com tom de irritação. Esse motivo, somado aos outros argumentos suscitados pelo Requerente, levaram a Corte a aceitar a impugnação do Coárbitro.

\subsection{Caso no 2 de Impugnação no Curso do Procedimento}

\subsubsection{Fundamentos da Impugnação}

Em recente caso da CCI, a Requerida impugnou um Árbitro devido à sua falta de revelação sobre o fato de que, na mesma data do recebimento de

\footnotetext{
85 Íntegra do art. 11(1) do Regulamento da CCI: "Todo árbitro deverá ser e permanecer imparcial e independente das partes envolvidas na arbitragem."

${ }^{86}$ Íntegra do art. 14(1) do Regulamento da CCI: "A impugnação de um árbitro por alegada falta de imparcialidade ou independência ou por quaisquer outros motivos deverá ser feita por meio da apresentação de uma declaração por escrito à Secretaria, especificando os fatos e circunstâncias que lhe servem de fundamento."
} 
suas Alegações Finais no procedimento ora analisado, o Árbitro havia apresentado um requerimento de uma nova arbitragem no qual constava como Advogado da Requerente contra a própria Requerida.

Tal fato estaria, a seu ver, ferindo gravemente os deveres de independência e imparcialidade esperados do Árbitro durante todo o procedimento arbitral. Teria ocorrido, assim, a perda de confiança da Parte no Árbitro, o que o impediria de continuar atuando no procedimento.

\subsubsection{Defesa}

O Árbitro impugnado negou qualquer violação ao dever de independência e imparcialidade uma vez que não atua como advogado da Requerente na nova arbitragem que havia sido suscitada pela Requerida.

Informou, ainda, que no passado seu escritório auxiliou a Requerente em alguns projetos, mas ele pessoalmente nunca teve nenhuma relação com tais atividades. Nesse sentido, alegou que ele e seu escritório são duas entidades distintas, e que o segundo conta com mais de 20 outros sócios.

A Requerente também nega a participação do Árbitro como seu advogado no novo procedimento arbitral e diz ainda que a impugnação é uma estratégia da Requerida para atrasar o andamento do procedimento.

Afirma, por fim, que, de acordo com o Princípio Geral $n^{\circ} 6$ das Diretrizes da IBA, a diferenciação entre a pessoa do Árbitro e a figura de seu escritório pode ser realizada. Dessa forma, nem sempre haveria o imediato sinal de quebra da independência ou imparcialidade do Árbitro por fatos que envolvam seu escritório. 


\subsubsection{Decisão sobre a Impugnação}

Uma vez que a impugnação foi feita dentro do prazo previsto pela CCI, a Corte passou à análise de seu mérito.

Inicialmente, sobre a atuação do Árbitro como Advogado da Parte, informou que três dos vinte sócios do escritório do Árbitro de fato estavam defendendo a Requerente no outro procedimento existente contra a Requerida, mas seu nome não constava entre eles.

Entendeu, assim, que poderia sim haver em algum grau dependência econômica entre o Advogado e a Parte e que ele também poderia, devido à atuação sua atuação como Árbitro, receber informações que pudessem auxiliar os demais membros de seu escritório no outro procedimento envolvendo as mesmas Partes.

Concordou, também, com o argumento de que o Árbitro descumpriu seu dever de revelação ao não informar sobre a atuação de seu escritório no segundo caso.

Por tais motivos, a Corte da CCI aceitou a impugnação do Árbitro e determinou a sua substituição.

\subsection{Caso no 1 de Impugnação após a Sentença}

Recente caso brasileiro pode ser estudado como exemplo de impugnação de Árbitro depois da Sentença Arbitral Final, ou seja, ao fim do procedimento ${ }^{87}$.

\footnotetext{
${ }^{87}$ Tendo em vista a confidencialidade do procedimento a ser estudado, os nomes das Partes e dos Árbitros, bem como características que permitam identificá-los, serão preservados.
} 


\subsubsection{Fundamentos da Impugnação}

No momento da Instauração do Procedimento Arbitral, quando do envio do Questionário de Conflito de Interesse e Disponibilidade, o Coárbitro indicado pela Parte Requerente do Procedimento, neste trabalho denominado Coárbitro X, fez a revelação de que havia atuado em favor da Parte que a indicou (aqui denominada Parte Indicadora) em ação judicial, durante 4 (quatro anos). Importante ressaltar, para fins de futuras análises e considerações, que o fim do referido período de 4 (quatro) anos havia se dado aproximadamente 9 (nove) anos antes da apresentação do Requerimento da Arbitragem ora estudada.

Apesar de tal revelação, dias após o protocolo da Sentença Final Arbitral pelo Tribunal Arbitral, a Parte Impugnante apresentou Impugnação ao Coárbitro X, alegando que o mesmo teria deixado de revelar, ao início do procedimento, questões relevantes para a aferição da sua confiança.

As informações alegadamente omitidas seriam as de que (i) o Coárbitro $\mathrm{X}$ não havia apresentado renúncia do mandato judicial de representação da Parte Indicadora no processo judicial em que, juntamente com seu cônjuge constava como seu advogado e (ii) no mesmo processo, quando já iniciada a disputa arbitral, foi interposto recurso de agravo de instrumento em que ambos (Coárbitro $\mathrm{X}$ e cônjuge) permaneciam como advogados da causa.

Apesar de tais fatos já serem anteriores ou ao menos concomitantes com o procedimento arbitral, o que os impede de serem analisados como fatos novos, a Parte Impugnante, por meio de Ata Notarial, alegou que só teve acesso às informações cerca de uma semana após o recebimento da Sentença Arbitral Final. 
Foi, portanto, a partir de tais alegações que a Parte Impugnante suscitou a infração aos artigos $5.2(\mathrm{~d})$ e $(1)^{88}$ e $5.3^{89}$ do Regulamento do CAM/CCBC, assim como a aplicação dos itens 2.3.1 e 2.3.9 da Lista Vermelha $^{90}$ e 3.1.1, 3.1.4 e 3.2.1 da Lista Laranja ${ }^{91}$ do IBA Guidelines.

\subsubsection{Defesa}

O Coárbitro impugnado, em sua Resposta à Impugnação, afirmou que já havia revelado sua atuação profissional a favor da Requerente no Questionário de Conflito de Interesse e de Disponibilidade e, assim, de acordo com o art. 5.4 do Regulamento do $\mathrm{CAM} / \mathrm{CCBC}^{92}$, o pleito da Impugnante estaria precluso.

Levantou, ainda, o argumento de que as informações fornecidas no Questionário apenas corroboram sua boa-fé e adequada postura profissional. Além disso, afirmou que o revelado em seu Questionário era suficiente para realizar o standard subjetivo de revelação. Dessa forma, caso a Parte

\footnotetext{
88 Íntegra do Art. 5.2 do Regulamento do CAM-CCBC: "Não pode ser nomeado árbitro aquele que: (...) "(d) for cônjuge, parente, consangüíneo ou afim, em linha reta ou colateral, até segundo grau, do advogado ou procurador de uma das partes"; "(1) tenha interesse econômico relacionado com qualquer das partes ou seus advogados, salvo por expressa concordância das mesmas.".

89 Íntegra do Art. 5.3 do Regulamento do CAM-CCBC: "Compete ao Árbitro declarar, a qualquer momento, seu eventual impedimento e recusar sua nomeação, ou apresentar renúncia."

${ }^{90} 2.3 .1$ "O árbitro atualmente representa ou presta consultoria a uma das partes ou a uma afiliada de uma das partes."

2.3.9 "Um familiar próximo do árbitro possui interesse financeiro ou pessoal significativo numa das partes ou numa afiliada de uma das partes."

91 3.1.1 "O árbitro atuou, nos três anos anteriores, como mandatário de uma das partes ou de uma afiliada de uma das partes, ou prestou assessoria jurídica ou foi consultado pela parte ou por uma afiliada da parte que o indicou em assunto não relacionado, mas o árbitro e a parte, ou afiliada desta, não têm uma relação permanente."

3.1.4 "A sociedade de advogados do árbitro atuou, nos três últimos anos, para ou contra uma das partes, ou uma afiliada de uma das partes, em assunto não relacionado, sem o envolvimento do árbitro.

3.2.1 "A sociedade de advogados do árbitro presta atualmente serviços a uma das partes, ou a uma afiliada de uma das partes, sem que tal constitua uma relação comercial significativa para tal sociedade e sem o envolvimento do árbitro".

92 Íntegra do art. 5.4. do Regulamento do CAM-CCBC: "As partes poderão impugnar os árbitros por falta de independência, imparcialidade, ou por motivo justificado no prazo de 15 (quinze) dias do conhecimento do fato, sendo a impugnação julgada por Comitê Especial constituído por 3 (três) membros do Corpo de Árbitros nomeados pelo Presidente do CAM-CCBC".
} 
Impugnante desejasse, poderia, naquele momento, suscitar dúvidas, pedir esclarecimentos e minudência, ou até mesmo objetar a sua indicação.

Sobre a ausência de Renúncia do Mandato Judicial, afirmou que a total ausência de atos processuais por mais de uma década, figurando o seu nome apenas no cabeçalho de algumas peças, traduziria renúncia por comportamento concludente.

No que tange à sua independência, o Coárbitro $\mathrm{X}$ afirmou ter demonstrado não haver recebido honorários profissionais da Parte Indicadora desde 2004, e seu cônjuge, desde 2011, sendo igualmente certo não lhes serem devidos honorários sucumbenciais relacionados ao processo judicial mencionado na Impugnação.

Diante disso, o Coárbitro X solicitou (i) o desprovimento das alegações de violação à imparcialidade e independência e da consequente nulidade suscitada, e (ii) a declaração de preclusão do pedido formulado pela Parte Impugnante.

A Parte Indicadora, no mesmo sentido que o fez o Coárbitro $\mathrm{X}$, sustentou que estaria precluso o direito da Parte Impugnante. A seu ver, as afirmações apresentadas pela Impugnante sobre o momento de conhecimento dos fatos que sustentam a Impugnação seriam uma tentativa de burlar o art. 5.4 do Regulamento do CAM-CCBC ${ }^{93}$, já que o Coárbitro X havia revelado sua relação passada com a Parte Indicadora no momento de sua nomeação.

Além disso, alegou não ser razoável crer que a Parte Impugnante tenha buscado informações sobre o processo judicial após a Sentença Arbitral. Isso

\footnotetext{
${ }^{93}$ Íntegra do art. 5.4 do Regulamento do CAM-CCBC: “As partes poderão impugnar os árbitros por falta de independência, imparcialidade, ou por motivo justificado no prazo de 15 (quinze) dias do conhecimento do fato, sendo a impugnação julgada por Comitê Especial constituído por 3 (três) membros do Corpo de Árbitros nomeados pelo Presidente do CAM-CCBC."
} 
porque, se a Parte Impugnante estivesse realmente se sentindo desconfortável com o fato revelado, poderia, na época, ter solicitado maiores detalhes sobre o processo. Alega, ainda, que a Parte só se mostrou incomodada com o fato após o recebimento da Sentença que lhe foi desfavorável.

A respeito da imparcialidade e independência do Coárbitro X, a Parte Indicadora sustentou que (i) a decretação da nulidade da Sentença Arbitral dependeria da comprovação de que o fato não revelado teria o condão de impedir a atuação do Coárbitro X com independência e imparcialidade e que, no caso em análise, (ii) a Parte Impugnante não comprovou de que modo o fato não revelado teria influenciado a atuação do Coárbitro $\mathrm{X}$ no procedimento arbitral, mais especificamente a Sentença Arbitral, proferida de forma unânime pelo Tribunal Arbitral.

\subsubsection{Decisão sobre a Impugnação}

O Tribunal Arbitral proferiu a sua Decisão sobre a Impugnação com base na Lei de Arbitragem, no Regulamento do CAM-CCBC e nas IBA Guidelines.

Inicialmente, o Comitê Especial discorreu acerca da permanência do Tribunal Arbitral após a prolação da Sentença Arbitral Final. Nesse aspecto, afirmou que, uma vez que as Partes apresentaram Pedidos de Esclarecimentos da Sentença, ainda não havia ocorrido o functus officio ${ }^{94}$ dos membros do Tribunal Arbitral e, assim, eles ainda podiam ser impugnados.

\footnotetext{
94 "The functus officio doctrine dictates that, once arbitrators have fully exercised their authority to adjudicate the issues submitted to them, their authority over those questions is ended, and the arbitrators have no further authority, absent agreement by the parties, to redetermine those issues."( T. Co Metals, LLC v. Dempsey Pipe \& Supply, 592 F.3d 329, 342 (2d Cir. 2010). Disponível em:https://www.courtlistener.com/opinion/1356933/t-co-metals-llc-v-dempsey-pipe-supply-inc/. Acessado em: 07/06/2019)
} 
Feita essa digressão, o Comitê Especial adentrou na temática da tempestividade, analisando os elementos que comprovariam ter a Parte Impugnante conhecido os fatos que baseavam a Impugnação do Coárbitro $\mathrm{X}$ em um momento posterior à prolação da Sentença Arbitral Final.

Apontou ainda para o fato de que tal exame deveria ainda considerar o estágio do procedimento arbitral, que estava na iminência de encerramento. Tal consideração revelou-se importante uma vez que a nulidade dos atos praticados, bem como os custos financeiros e temporais incorridos por ambas as Partes são apenas algumas das consequências que o acolhimento de uma impugnação submetida ao final do procedimento arbitral poderia acarretar.

O Comitê Especial entendeu da análise dos fatos que as declarações unilaterais da Parte Impugnante eram insuficientes para determinar, com a certeza necessária, o momento em que a Parte Impugnante teve conhecimento da demanda judicial que servia de base para a Impugnação.

Suscitou, ainda, o dever de investigar da Parte Impugnante uma vez que a revelação feita pelo Coárbitro $\mathrm{X}$ no início do procedimento arbitral já seria suficiente para gerar na Parte Impugnante uma curiosidade de investigação e, por consequência, o dever de aprofundar questionamentos, requerer esclarecimentos adicionais ou até mesmo objetar a nomeação. Estaria qualificada, portanto, a preclusão do direito da Parte Impugnante de impugnar o Coárbitro $X$.

\subsection{Caso no 2 de Impugnação após a Sentença}

\subsubsection{Fundamentos da Impugnação}

Uma situação curiosa foi motivo de pedido de impugnação em um procedimento da CCI. 
Um Coárbitro, inadvertidamente e por engano, enviou à Requerente a minuta da Sentença Arbitral Final que estava sendo discutida pelo Tribunal Arbitral. Depois que o erro foi identificado e avisado ao Presidente do Tribunal Arbitral pela própria Parte, foi pedido que as Partes desconsiderassem o e-mail recebido por engano.

A Requerida, em resposta, disse que esse era um erro extremamente grave e que, portanto, o e-mail não poderia ser simplesmente ignorado. Analisou o documento que lhe foi enviado e, ao discordar com a minuta, criticou o raciocínio e a decisão adotados, afirmando que não houve respeito ao princípio do contraditório.

A Requerida fundamenta a impugnação na violação do art. 22.4 do Regulamento da $\mathrm{CCI}^{95}$.

\subsubsection{Defesa}

O Árbitro impugnado, que enviou a minuta da Sentença à Parte alegou, em sua defesa que não teve culpa no envio da minuta à Parte, e que seu computador havia sido hackeado. Informou, ainda, que nunca falou diretamente com nenhuma das Partes envolvidas no procedimento.

\subsubsection{Decisão sobre a Impugnação}

Ao indicar a tempestividade da apresentação da impugnação, a Corte da CCI passou à análise da alegada violação ao segredo de deliberação e do dever de imparcialidade.

\footnotetext{
95 Íntegra do art. 22.4 do Regulamento da CCI: "Em todos os casos, o tribunal arbitral deverá atuar de forma equânime e imparcial, devendo sempre assegurar que cada parte tenha tido a oportunidade de apresentar as suas razões."
} 
Sobre o primeiro aspecto, informou que não há qualquer tipo de proibição formal que impeça o envio de minutas de Sentenças às Partes. Disse, ainda, que a análise dos fatos e das provas estudados demonstraram que claramente não houve intenção por parte do Árbitro de enviar a minuta à Parte, mas sim ao Presidente do Tribunal Arbitral.

Passando ao segundo argumento, de violação ao dever de imparcialidade, a Corte reiterou que todo Tribunal Arbitral lhe envia antes de enviar às Partes a minuta da Sentença ${ }^{96}$. Dessa forma, não caberia às Partes comentar sobre o raciocínio feito pelo Tribunal em sua decisão.

Para sanar eventuais insatisfações da Parte para com o resultado final concretizado na Sentença Arbitral, deve-se recorrer às soluções previstas no art. 36 do Regulamento da $\mathrm{CCI}^{97}$, e não usar inadequadamente e de forma atécnica o instituto da impugnação.

\footnotetext{
${ }^{96}$ Íntegra do art. 34 do Regulamento da CCI: "Exame prévio da sentença arbitral pela Corte. Antes de assinar qualquer sentença arbitral, o tribunal arbitral deverá apresentá-la sob a forma de minuta à Corte. A Corte poderá prescrever modificações quanto aos aspectos formais da sentença e, sem afetar a liberdade de decisão do tribunal arbitral, também poderá chamar a atenção para pontos relacionados com o mérito do litígio. Nenhuma sentença arbitral poderá ser proferida pelo tribunal arbitral antes de ter sido aprovada quanto à sua forma pela Corte."

97 Íntegra do art. 36 do Regulamento da CCI: "Correção e interpretação da sentença arbitral; devolução de sentenças arbitrais 1 Por iniciativa própria, o tribunal arbitral poderá corrigir qualquer erro material, de cálculo ou tipográfico, ou quaisquer erros similares encontrados na sentença arbitral, desde que tal correção seja submetida à aprovação da Corte dentro do prazo de 30 dias a partir da data da prolação da sentença. 2 Qualquer pedido de correção de um erro do tipo referido no artigo 36(1), ou quanto à interpretação de uma sentença arbitral, deverá ser feito à Secretaria dentro de 30 dias contados da notificação da sentença às partes, no número de cópias estipulado no artigo $3^{\circ}(1)$. Depois da apresentação do pedido ao tribunal arbitral, este deverá conceder à outra parte um prazo curto, não superior a 30 dias, a partir do recebimento do pedido feito pela parte adversa, para que sejam apresentadas as suas observações. O tribunal arbitral deverá apresentar a minuta de sua decisão quanto ao pedido à Corte em até 30 dias após o término do prazo para o recebimento das observações da outra parte ou dentro de qualquer outro prazo fixado pela Corte. 3 A decisão de corrigir ou de interpretar a sentença arbitral deverá ser proferida sob a forma de um addendum, que constituirá parte integrante da sentença arbitral. As disposições dos artigos 32, $34 \mathrm{e}$ 35 serão aplicadas mutatis mutandis. 4 Quando um órgão judicial devolver uma sentença arbitral ao tribunal arbitral, as disposições dos artigos 32, 34 e 35 e o presente artigo 36 serão aplicadas mutatis mutandis a qualquer addendum ou sentença arbitral proferida de acordo com os termos determinados pelo poder judiciário. A Corte poderá adotar qualquer medida que entenda necessária para permitir que o tribunal arbitral cumpra os termos da decisão judicial e poderá fixar uma provisão para cobrir quaisquer despesas e honorários adicionais do tribunal arbitral e qualquer despesa administrativa adicional da CCI."
} 


\section{CONCLUSÃO}

Conforme exposto ao longo deste trabalho, a condução, análise e julgamento do Procedimento Arbitral devem ser, a todo momento, acompanhadas da independência e da imparcialidade do Árbitro. Ou seja, cabe a ele atuar sem estar previamente decidido a agir em prol de uma ou outra Parte por quaisquer motivos que não sua interpretação dos fatos e argumentos que lhe foram apresentados.

A fim de propiciar o cumprimento eficiente e rigoroso do dever de independência e imparcialidade dos Árbitros surgem através da doutrina, de leis que versam sobre arbitragem e Regulamentos das Câmaras, dois novos deveres, aqui chamados de Dever de Revelar e Dever de Investigar.

O primeiro, Dever de Revelar, dirige-se ao Árbitro que deve, desde sua nomeação até o final da jurisdição do Tribunal Arbitral ${ }^{98}$, informar às Partes sobre quaisquer fatos e situações que possam colocar em risco sua independência ou imparcialidade. A fim de auxiliar os Árbitros no cumprimento de tal dever, é de praxe que leis de arbitragem e Regulamentos apresentem um rol exemplificativo do que deve ser revelado. Como visto, a maior parte dessas listas é elaborado com base nas IBA Guidelines.

O Dever de Investigar, por sua vez, é direcionado às Partes e ainda pouco difundido. Trata-se da ideia de que, somado ao Dever de Revelar dos Árbitros, há um dever das próprias Partes de, na medida do possível, buscar novas informações sobre aquele Árbitro e, principalmente, se aprofundar naquelas situações por ele reveladas. Para tanto, pode-se recorrer não só à meios usuais de busca, como internet e bases de dados, como também pedir informações adicionais e esclarecimentos ao próprio Árbitro.

\footnotetext{
${ }^{98}$ Considerou-se, nesse trabalho, que o fim da jurisdição do Tribunal Arbitral se dá com a prolação da Sentença Arbitral Final ou da Decisão sobre Pedidos de Esclarecimentos da Sentença Arbitral.
} 
Compreendida as delimitações de cada um desses conceitos e deveres, passamos à análise de suas aplicações em cada um dos diferentes momentos de um Procedimento Arbitral, que foram: (i) quando da indicação do Árbitro, ou seja, antes da assinatura do Termo de Arbitragem; (ii) durante o curso do procedimento, isto é, entre a assinatura do Termo de Arbitragem e a prolação da Sentença Arbitral Final; e (iii) no período compreendido entre a prolação da Sentença Arbitral Final e o fim do prazo para a Decisão sobre Pedidos de Esclarecimentos.

Conforme pudemos perceber, a medida em que o procedimento está mais avançado, os requisitos para a impugnação e seu consequente afastamento do Árbitro da condução do procedimento vão sendo analisados cada vez com maior rigor.

Tal fato decorre da necessidade de se preservar o procedimento, em vista de todos os investimentos de tempo e dinheiro nele depositados. Há, portanto, uma imperiosa necessidade de ponderação entre o direito das Partes de impugnação do Árbitro e o dever, não só do Árbitro, mas de todos os envolvidos no procedimento arbitral (Tribunal Arbitral, Partes e Câmara) de envidar seus melhores esforços para preservar a integridade do procedimento arbitral.

Por estes motivos, pôde-se perceber que, enquanto no início do procedimento a análise da independência e da imparcialidade é feita de forma mais abstrata, ou seja, de quanto aquilo poderia influenciar no julgamento da controvérsia e prejudicar alguma das Partes em benefício da outra. Já nos casos em que a impugnação é suscitada ao fim do procedimento, analisa-se a independência e a imparcialidade como dados concretos, ou seja, em que medida determinados atos do Árbitro de fato representaram uma violação ao dever de independência e imparcialidade e, não apenas se, mas também o quanto, isso prejudicou a devida condução e julgamento da lide. 
Importa concluir que esse progressivo rigor com que tais fatores são analisados é essencial para que nenhuma das Partes se aproveite de um instituto tão grave e delicado quanto o da impugnação do Árbitro por violação da independência ou da imparcialidade com o único objetivo de tumultuar e atrasar o fim do procedimento ou, ainda, de se insurgir contra uma decisão que lhe foi desfavorável e, com isso, ter que reiniciar todo o procedimento. 


\section{REFERÊNCIAS BIBLIOGRÁFICAS}

BAPTISTA, Luiz Olavo. Arbitragem comercial e internacional. São Paulo: Lex Editora, 2011.

BAPTISTA, Luiz Olavo. Dever de revelação do árbitro: extensão e conteúdo. Inexistência de infração. Impossibilidade de anulação da Sentença Arbitral. Revista de Arbitragem e Mediação, Jan-Mar 2013, vol. 36/2013, pp. 199218.

BERALDO, Leonardo de Faria. Curso de Arbitragem: nos termos da Lei $n^{o}$ 9.307/96. São Paulo: Atlas, 2014.

BENEDETTELli, Massimo V., CONSOLO, Claudio e RADICATI DI BROZOLO, Luca. Commentario breve al diritto dell'arbitrato nazionale ed internazionale. Milão: Casa Editrice Dott. Antonio Milani, 2010.

BORN, Gary. B. International Commercial Arbitration (Second Edition), 2nd Edition. Kluwer Law International, 2014.

CASEY, J. Brian. Selection of the Tribunal. In: HANESSIAN, Grant e NEWMAN, Lawrence W. (Ed.). International Arbitration Checklists, Second Edition. New York: JurisNet, LLC, 2009.

CARMONA, Carlos Alberto. Arbitragem e processo: um comentário à Lei $n^{o}$ 9.307/96. 3 ed. rev., atual. e ampl. São Paulo: Atlas, 2009.

CLAY, Thomas. L'Arbitre. Paris: Dalloz, 2001.

Diretrizes da IBA relativas a Conflitos de Interesses em Arbitragem Internacional. Londres: International Bar Association, 2004.

DAELE, Karel. Challenge and disqualification of arbitrators in international arbitration. The Netherlands: Kluwer Law International, 2012.

DOLINGER, Jacob. O Árbitro da Parte - Considerações Éticas e Práticas. Revista Brasileira de Arbitragem, 2005, vol. II, issue 6, pp. 29-45. 
ELIAS, Carlos. O Árbitro. In: LEVY, Daniel e PEREIRA, Guilherme Setoguti J. (Coords.). Curso de Arbitragem. São Paulo: Thomson Reuters Brasil, 2018.

FERRAZ JÚNIOR, Tércio Sampaio. Suspeição e impedimento em arbitragem sobre o dever de revelar na Lei 9.307/1996. Revista de Arbitragem e Mediação, Jan-Mar 2011, vol. 28/2011, pp. 65-82.

FERRO, Marcelo Roberto. Apontamentos sobre a independência dos árbitros, in ADAMEK, Marcelo Vieira Von (Ed.). Temas de direito societário e empresarial contemporâneos. São Paulo: Malheiros, 2011, pp. 849-886.

FILHO, Napoleão (Eds.). The CAM-CCBC Arbitration Rules 2012: A Commentary. The Hague: Eleven International Publishing, 2016.

FORBES, Carlos Suplicy e KOBAYASHI, Patrícia S. Article 5 - Arbitral Tribunal. In: STRAUBE, Frederico José, FINKELSTEIN, Cláudio e CASADO FILHO, Napoleão (Eds.). The CAM-CCBC Arbitration Rules 2012: A Commentary. The Hague: Eleven International Publishing, 2016.

FRY, Jason; GREENBERG, Simon e MAZZA, Francesca. The Secretariat's Guide to ICC Arbitration: A Practical Commentary on the 2012 ICC Rules of Arbitration from the Secretariat of the ICC International Court of Arbitration. Paris: International Chamber of Commerce (ICC), 2012.

GAILLARD, Emmanuel e SAVAGE, Jonhn (Ed.). Fouchard, Gaillard, Goldman on International Commercial Arbitration, vol. I. Londres: Wolters Kluwer, 1999.

GREBLER, Eduardo. A Ética dos Árbitros. Revista Brasileira de Arbitragem, 2013, vol. X, issue 40, pp. 72-77.

HENRI, Marc. Le devoir de l'indépendence de l'arbitre. 1 ed. Paris: LGDJ, 2001.

JÚDICE, José Miguel. Árbitros: Características, perfis, poderes e deveres. Revista de Arbitragem e Mediação, Jul-Set 2009, vol. 22, pp. 119-146. 
KULL, Nadja Jaisli e ROTH, Andrea. Chapter II: The Arbitrator and the Arbitration Procedure, Challenging Arbitrators for Lack of Independence or Impartiality: Procedural Pitfalls from a Swiss Perspective. In: KLAUSEGGER, Christian, KLEIN, Peter et al. (Eds.). Austrian Yearbook on International Arbitration 2019, pp. 223-248.

LEE, João Bosco e PROCOPIAK, Maria Cláudia de Assis. A Obrigação de Revelação do Árbitro - Está influenciada por Aspectos Culturais ou Existe um Verdadeiro Standard Universal? Revista Brasileira de Arbitragem, 2007, vol. IV, issue 14, pp. 9-22.

Lei Modelo da UNCITRAL sobre Arbitragem Comercial Internacional de 1985, com alterações adotadas em 2006.

LEITE, António Pinto. Independência, Imparcialidade e Suspeição de Árbitro. Revista Brasileira de Arbitragem, 2010, vol. VII, issue 25, pp. 104118.

LEMES, Selma Maria Ferreira. A Independência e a Imparcialidade do Árbitro e o Dever de Revelação. Revista Brasileira de Arbitragem, 2010, vol. VII, issue 26, pp. 21-34.

LEMES, Selma Maria Ferreira. O Procedimento de Impugnação e Recusa de Árbitro, como sistema de controle quanto à independência e a imparcialidade do julgador. Revista de Arbitragem e Mediação, Jul-Set 2016, vol. 50/2016, pp, 369-386.

LUCON, Paulo Henrique dos Santos. Imparcialidade na arbitragem e impugnação aos árbitros. Revista de Arbitragem e Mediação. Out-Dez 2013, vol. 39/2013, pp. 39-51.

MARQUES, Ricardo Dalmaso. Breves Apontamentos sobre a Extensão do Dever de Revelação do Árbitro. Revista Brasileira de Arbitragem, 2011, vol. VIII, issue 31, pp. 59-84.

MARTINS, Pedro A. Batista. Dever de Revelar do Árbitro. Revista de Arbitragem e Mediação, Jan-Mar 2013, vol. 36/2013, pp. 219-229.

MENEZES, Caio Campello de. Como Barrar as Táticas de Guerrilha em Arbitragens Internacionais? Revista Brasileira de Arbitragem, 2015, vol. XII, issue 45, pp. 82-107. 
Notas às Partes e aos Tribunais Arbitrais sobre a Condução da Arbitragem conforme o Regulamento de Arbitragem da CCI, $1^{\circ}$ de janeiro de 2019.

NUNES PINTO, José Emílio. Recusa e Impugnação de Árbitro. Revista de Arbitragem e Mediação, Out-Dez 2007, vol. 15/2007, pp. 80-84.

PROCOPIAK, Maria Cláudia de Assis. As diretrizes do International Bar Association sobre Conflitos de Interesses na Arbitragem Internacional. Revista Brasileira de Arbitragem, 2007, vol. IV, issue 16, pp. 7-40.

PUCCI, Adriana Noemi. O árbitro na arbitragem internacional. Princípios éticos. Arbitragem Comercial Internacional (Coord.). São Paulo: LTr, 1998.

PUCCI, Adriana Noemi. Impugnação de Árbitros. In: CARMONA, Carlos Alberto, LEMES, Selma Ferreira e MARTINS, Pedro BATISTA. 20 anos da lei de arbitragem: Homenagem a Petrônio R. Muniz. São Paulo: Atlas, 2017.

REDFERN, Alan; HUNTER, Martin; BLACKABY, Nigel e PARTASIDES, Constantine. Law and Practice of International Comrnercial Arbitration. Oxford: Oxford University Press, 2009.

Regulamento de Arbitragem do CAM-CCBC, de $1^{\circ}$ de setembro de 2011, com alterações aprovadas em 28 de abril de 2016.

Regulamento de Arbitragem da CAMARB, de setembro de 2017.

Regulamento de Arbitragem da CCI, em vigor a partir de $1^{\circ}$ de março de 2017

Regulamento de Arbitragem da LCIA, de $1^{\circ}$ de outubro de 2014

VERÇOSA, Fabiane. A liberdade das partes na escolha e indicação de árbitros em arbitragens internacionais: limites e possibilidades. Revista de Arbitragem e Mediação, Jan-Abr 2004, vol. 1, pp. 332-350.

WALD, Arnoldo. A Ética e a Imparcialidade na Arbitragem. Revista de Arbitragem e Mediação, Out-Dez 2013, vol. 39/2013, pp. 17-37. 
WALD, Arnoldo; BORJA, Ana Gerdau; LONGO, Bryan; TERASHIMA, Eduardo Ono; VIEIRA, Maíra de Melo; CASADO FILHO, Napoleão e GAGLIARDI, Rafael Villar. Article 4-Commencement of the Arbitration. In: STRAUBE, Frederico José, FINKELSTEIN, Cláudio e CASADO 